\title{
A Physically-based Modelling to Predict the Cyclic Voltammetry Response of LSCF-type Electrodes: Impact of the Ohmic Losses and Microstructure
}

\author{
E. Effori ${ }^{(1)}$, J. Laurencin ${ }^{(1)}$, V. Tezyk ${ }^{(1)}$, C. Montella ${ }^{(2)}$, L. Dessemond $^{(3)}$, E. Siebert ${ }^{(3)}$ \\ ${ }^{(1)}$ Univ. Grenoble Alpes - CEA/LITEN, 17 rue des Martyrs, 38054, Grenoble, France \\ ${ }^{(2)}$ Univ. Grenoble Alpes, Univ. Savoie Mont Blanc, CNRS, Grenoble INP, LEPMI, 38000 Grenoble, France (Retired) \\ ${ }^{(3)}$ Univ. Grenoble Alpes, Univ. Savoie Mont Blanc, CNRS, Grenoble INP, LEPMI, 38000 Grenoble, France
}

\begin{abstract}
Two numerical models have been developed to simulate the Cyclic Voltammetry (CV) response of Lanthanum Strontium Cobalt Ferrite (LSCF) porous electrode at high temperature. The first one (model-I) takes into account the solid-state diffusion in LSCF coupled with a global reaction of oxygen exchange while the second one (model-II) is based on a detailed elementary description of the reaction mechanism. The relevance of model-II to predict the voltammograms has been checked with experimental data obtained at different operating temperatures and imposed scan rates. The $\mathrm{CV}$ response of porous and quasi-dense electrodes has been studied with the two models and has been discussed in the frame of the zone diagram method. It has been shown that the peaks of the voltammograms are due to the transient change of the oxygen stoichiometry in LSCF. As this evolution is mainly governed by the oxygen diffusion in the material coupled to the reaction of oxygen exchange, it has been established that model-I can provide a satisfactory approximation of the CV curves if the exchange rate constant $k_{\text {chem }}$ is determined far from equilibrium. It has been also shown that the voltammograms are strongly distorted by the Ohmic losses making their interpretation impossible in practice, under the classical operating conditions of the solid oxide cells. To overcome this limitation, a methodology based on the modelling approach has been proposed to remove the Ohmic losses from the voltammograms and hence to reveal the voltammetry peaks. Finally, the impact of the LSCF decomposition on the CV response has been estimated with model-II. It has been established that the surface passivation and the decrease of the chemical diffusivity can substantially affect the shape of the voltammograms.
\end{abstract}

Keywords: Cyclic voltammetry, modeling, Solid Oxide Cells, LSCF, demixing. 


\section{Introduction}

Solid Oxide Cells (SOCs) are electrochemical devices able to convert the chemical energy stored inside a fuel into electricity (i.e. solid oxide fuel cell - SOFC - mode) or vice versa (i.e. solid oxide electrolysis cell - SOEC - mode). The high operating temperature $\left(750^{\circ} \mathrm{C}\right.$ $850^{\circ} \mathrm{C}$ ) leads to many advantages such as a high efficiency, a large fuel flexibility and a good reversibility in SOFC and SOEC modes [1,2]. If combined with renewable energy sources, these characteristics make SOCs one of the most promising technology for an environmentalfriendly energy production and storage. However, its spread on the market place is still hindered by the high material degradation that reduces substantially the cell lifetime. Indeed, the elevated operating temperature enhances the reactivity between the cell components and the microstructural evolutions leading to many detrimental phenomena, such as the formation of non-conducting secondary phases, material agglomeration or electrode poisoning $[3,4,5$, 6]. SOCs are usually composed by a dense ionic conductor electrolyte sandwiched between two porous electrodes. The electrolyte is usually made of Yttria Stabilized Zirconia (YSZ), while the hydrogen electrode is a cermet of Nickel and YSZ (Ni-YSZ) [7]. The oxygen electrode is usually made of materials exhibiting a Mixed Ionic and Electronic Conductivity (MIECs) [8]. Among them, the Lanthanum Strontium Cobalt Ferrite family (LSCF) is extensively used since it presents both good performances and an acceptable long-term stability at intermediate temperatures $\left(650{ }^{\circ} \mathrm{C}-750{ }^{\circ} \mathrm{C}\right)[9,10]$. Nevertheless, it has been shown that a substantial part of the overall cell degradation comes from the oxygen electrode demixing $[11,12]$. Indeed, the LSCF decomposition induces a loss of ionic conductivity along with a surface passivation for the reaction of oxygen exchange with harmful consequences on the global electrode efficiency $[13,14,15,16]$. Since the degradation is strictly dependent on the phenomena taking place at the microscopic level, a deep knowledge of the Oxygen Electrode Reaction (OER) mechanism is necessary to analyze the degradation. Nowadays, it is widely recognized that the OER for LSCF electrode is dominated under cathodic polarization (SOFC mode) by the so called 'bulk path', consisting in the oxygen incorporation at the LSCF surface followed by a solid-state diffusion in the material [17, 18, 19, 20]. However, we have recently considered the coexistence of a second parallel pathway, called 'surface' path defined as the direct oxidation/reduction at the Triple Phase Boundaries lengths (TPBls) [21]. The predominance of one path over the other is strongly dependent on the operating conditions (polarization, temperature and oxygen partial pressure) and LSCF composition [21, 22, 23, 24]. In this frame, it has been shown that the surface path is activated under anodic polarization (SOEC mode). Moreover, it has been demonstrated that several 
steps limit simultaneously the reaction rate on the classical porous $\mathrm{La}_{0.6} \mathrm{Sr}_{0.4} \mathrm{Co}_{0.2} \mathrm{Fe}_{0.8} \mathrm{O}_{3-\delta}$ electrode [24].

Therefore, a complete set of electrochemical characterizations appears to be necessary for the interpretation of the OER mechanism for LSCF. The most common technique used to study the electrochemical behavior of MIECs is the Electrochemical Impedance Spectroscopy (EIS) usually associated with the acquisition of steady-state polarization curves (i-V curves) [25, 26, 27]. In complementary with these methods, Cyclic Voltammetry (CV) measurements can be performed to analyze the non-linear part of the electrode response. Nevertheless, very few experimental data can be found in the literature on the response of MIEC materials involved in SOCs [28, 29, 30] and even fewer are focused on the LSCF electrode [31, 32, 33]. Recently, Tezyk et al. [34] have investigated the dependence of the CV response on the microstructural parameters and the oxygen partial pressure, for the typical $\mathrm{La}_{0.6} \mathrm{Sr}_{0.4} \mathrm{Co}_{0.2} \mathrm{Fe}_{0.8} \mathrm{O}_{3-\delta}$ composition deposited on a Ceria doped Gadolinium Oxide (CGO $\mathrm{Ce}_{0.9} \mathrm{Gd}_{0.1} \mathrm{O}_{2-\delta}$ ) electrolyte. The authors concluded that both the electrode specific surface area $S_{p}^{L S C F}$ and the oxygen partial pressure $P_{O_{2}}$ play a key role on the $\mathrm{CV}$ response. Indeed, when these two parameters are decreased, the reaction of oxygen exchange at the electrode surface becomes sufficiently limiting to allow the transient oxygen storage or depletion inside LSCF under dynamic polarization. This phenomenon results in the enhancement of both the intensity of the $\mathrm{CV}$ peaks and the series resistance $R_{s}$ under cathodic dc bias. However, it is worth mentioning that (i) this previous experimental study was performed at lower temperatures than those used in the SOCs technology, and (ii) the electrolyte Ohmic drop, hard to compensate, was found to strongly distort the CV curves making the interpretation of experimental results very difficult. In this frame, a modelling approach could be an efficient tool to ensure a better analysis for the complex $\mathrm{CV}$ response.

To date, many models have been proposed to simulate the polarization curves and the impedance diagrams for MIEC electrodes [21, 35, 36, 37, 38,]. Among them, the so called Adler-Lane-Steel (ALS) model has to be mentioned as pioneer of the impedance calculation of porous mixed-conducting oxygen electrode at Open Circuit Potential (OCP) [17]. Those authors have expressed the OER mechanism as a solid-state diffusion, followed by a pure chemical reaction of oxygen exchange with the ambient atmosphere that results in a Gerischer-type element impedance under semi-infinite condition. Several models have been based on this simplified approach with improvements towards a more sophisticated description of the reaction mechanism [21, 36, 37]. As an illustration, some authors have 
implemented full elementary kinetic models for a better comprehension of the electrode surface behavior [24, 40, 41]. These models take into account the electrostatic surface potential at the MIEC/gas interface related to the presence of adsorbed charged species on the electrode surface [42, 43]. For example, Gong et al. [44] simulated a LSM-type cathode through a 1D-continuum model, in which the OER mechanism was divided into a multi-step process. Through the analysis of the polarization curves, the authors observed that the surface potential strongly affects the electrode kinetic by introducing rate-limiting steps. Besides, Effori et al. [24] extended a pre-existing model for the LSCF and LSCF-CGO oxygen electrodes, by decomposing the reaction mechanism into six elementary reaction steps. This elementary expression of the kinetic resulted in an improvement of the model capability to predict accurately the electrode dependence on $P_{O_{2}}$.

Despite the several aforementioned models, none of them was extended to simulate the CV curves. Only recently, we have proposed semi-analytical solutions for Linear Sweep Voltammetry (LSV) and CV curves of the OER on porous MIEC electrodes [45]. These solutions have been established by extending the ALS-based model for non-linear potential solicitations and by neglecting the Ohmic loss in the electrolyte. However, to the best of our knowledge, no numerical tool has been proposed for the simulation of this electrochemical technique.

In this work, the detailed full elementary model for the OER on LSCF electrode, described in [24] and validated for steady-state and impedance measurements, was extended to compute the CV curves as well. The model validation was carried out on experimental results recorded by testing a symmetrical LSCF cell, for different operating temperatures $\left(700{ }^{\circ} \mathrm{C}\right.$ and $\left.650{ }^{\circ} \mathrm{C}\right)$ and imposed scan rates, at $P_{O_{2}}=0.1$ atm. In addition, a numerical version of the semianalytical model, studied by Montella et al. [45], was developed, in order to take into account the Ohmic loss in the electrolyte. A comparison between the two models has been discussed to assess the relevance of the simplified approach (implemented semi-analytical model) with respect to the detailed one (full elementary model). Moreover, the effect of both the microstructural properties and the geometrical parameters on the $\mathrm{CV}$ curves has been investigated. Thanks to this analysis, a methodology was provided to overcome the problematic related to the distortion of the experimental CV curves by the Ohmic losses. Moreover, the impact of the LSCF demixing has been analyzed by decreasing both the specific surface area and the ionic conductivity. It can be noticed that the obtained results 
have been interpreted using the concept of zone diagram, described in our previous work [45] as an efficient method to identify the liming processes in the electrodes.

\section{Experiments and numerical tool}

\subsection{Sample, setup and experimental conditions}

A symmetrical button cell made of $\mathrm{La}_{0.6} \mathrm{Sr}_{0.4} \mathrm{Co}_{0.2} \mathrm{Fe}_{0.8} \mathrm{O}_{3-\delta}$ was prepared by screen-printing the electrodes on both sides of a circular 8YSZ electrolyte. A CGO barrier layer was added between the electrodes and the electrolyte to prevent the formation of secondary phases [5]. The symmetrical cell was tested using a three-electrode set-up, extensively described previously in [24]. A platinum wire ring was applied on the perimeter of the electrolyte membrane and used as Reference Electrode (RE). One of the LSCF electrodes was used as Working Electrode (WE) and the other as Counter Electrode (CE). It is worth mentioning that a particular attention was paid to fulfill the geometrical rules of the reference electrode positioning [46]. The cell was heated with a rate of $1{ }^{\circ} \mathrm{C} \cdot \min ^{-1}$ up to $800{ }^{\circ} \mathrm{C}$, under synthetic air (with a total $\mathrm{O}_{2}$ and $\mathrm{N}_{2}$ flow rates of $0.44 \mathrm{Nl} \cdot \mathrm{h}^{-1}$ and $1.66 \mathrm{Nl} \cdot \mathrm{h}^{-1}$, respectively). The sample was maintained at this temperature for 48 hours to improve the electrical contact between the electrodes and the current collectors. Before starting the measurements, the cell stabilization was monitored through the periodic record of impedance spectra at OCP. Afterwards, the electrochemical measurements were carried out at $700{ }^{\circ} \mathrm{C}$ and $650{ }^{\circ} \mathrm{C}$, under $P_{O_{2}}=0.1 \mathrm{~atm}$. The CV experiments were conducted by imposing, between the WE and RE, a triangular potential waveform, as described in Fig. 2a, starting from OCP in the anodic direction, with a demi-amplitude of $0.3 \mathrm{~V}$. The scan rate was applied with a potential step of $0.01 \mathrm{~V}$ from a minimum of $20 \mathrm{mV} \cdot \mathrm{s}^{-1}$ up to a maximum of $1000 \mathrm{mV} \cdot \mathrm{s}^{-1}$. Moreover, between each change of scan rate, the cell was maintained at OCP for a period of 30 minutes to allow the system returning to equilibrium before any subsequent measurement. The experiments were conducted using an Autolab potentiostat/impedance frequency analyzer (PGSTAT302N).

\subsection{ALS-based and full elementary model description}

In this work, a numerical version of the semi-analytical ALS-based model proposed in [45] for the CV response of the OER on porous LSCF electrode has been implemented in COMSOL Multiphysics ${ }^{\circledR}$. Moreover, the full elementary model proposed by [24] has been 
extended to simulate CV curves as well. The comparison between the two approaches will be discussed in section 3 .

ALS-based model - As this semi-analytical model has been already thoroughly detailed in [45], only a brief description, with the main assumptions, is reminded hereafter. The model considers a 1D homogenous electrode film connected from one side to the electrolyte $(\mathrm{z}=0)$ and to the opposite side to the current collector $(z=\ell)$ (Fig. 1a). The oxygen partial pressure is assumed as constant all along the electrode thickness. Therefore, the incorporated oxygen and vacancies in LSCF are the only species that can vary. The reaction mechanism is simply composed by the ionic transfer at the electrode/electrolyte interface (1a), followed by a solidstate diffusion coupled with a pure chemical reaction of the oxygen exchange between the gas and LSCF (1b) (Fig. 1b):

$$
\begin{gathered}
O^{2-}(\text { electrolyte })+V_{o}^{\bullet \bullet}(L S C F) \leftrightarrow O_{o}^{x}(L S C F) \text { at the electrolyte interface }(z=0) \\
O_{o}^{x}(L S C F) \leftrightarrow V_{o}^{\bullet \bullet}(L S C F)+1 / 2 O_{2}(\text { gas })+2 e^{-} \text {in the electrode thickness }(0< \\
z<l)
\end{gathered}
$$

where $O_{o}^{x}(L S C F)$ and $V_{o}^{\bullet \bullet}(L S C F)$ denote the incorporated oxygen and vacancies in LSCF.

In this approach, the double layer capacitance at electrode/electrolyte interface as well as the Ohmic drop in the electrolyte are neglected. Because of the high operating temperature, the reaction of ionic transfer is considered to occur in a quasi-equilibrium state. This condition allows expressing the concentration of oxygen in LSCF at the electrolyte interface $(z=0)$ through the Nernst's equation (used as a first boundary condition):

$$
C_{O_{o}^{x}}(0, t)=C_{O_{o}^{x}}^{\max } /\{1+\exp [-(\xi(t))]\} \quad \text { with } \quad C_{O_{o}^{x}}(0, t)=C_{O_{o}^{x}}^{\max }-C_{V_{o}^{*}}(0, t)
$$

where $C_{V_{o}^{*}}(0, t)$ and $C_{O_{o}^{x}}(0, t)$ represent the time dependent interfacial concentration of vacancies and oxygen in LSCF, respectively, while $C_{O_{o}^{x}}^{\max }$ is the maximum concentration of oxygen in the material. The dimensionless parameter $\xi(t)$ is related to the electrode potential as follows:

$$
\xi(t)=\frac{2 F}{R T}\left(E(t)-E^{0}\right)
$$

where $F$ is the Faraday's constant, $R$ the universal gas constant and $T$ the absolute temperature. The terms $E(t)$ and $E^{0}$ are referred as the time-dependent electrode potential and the standard potential, respectively. It is worth noting that equilibrium conditions are 
supposed to be fulfilled at $\mathrm{t}=0$ in such a way that $C_{O_{o}^{x}}^{e q}=C_{O_{o}^{x}}(z, 0), E^{e q}=E(0)$ and $\xi^{e q}=$ $\xi(0)$.

The kinetic rate for the oxygen exchange reaction between the electrode and the gas phase is written as a function of the incorporation level:

$$
v_{\text {chem }}(z, t)=S_{p}^{L S C F} k_{\text {chem }}\left(C_{o_{o}^{x}}(z, t)-C_{O_{o}^{x}}^{e q}\right) \text { for } 0<z<l
$$

where $k_{\text {chem }}$ and $S_{p}^{L S C F}$ are the chemical exchange rate constant and the electrode specific surface area, respectively. The flux of oxygen in the LSCF bulk is expressed with the classical Fick's law:

$$
J_{o_{o}^{x}}(\mathrm{z}, \mathrm{t})=-\frac{\varepsilon_{L S C F}}{\tau_{L S C F}} D_{c h e m} \frac{\partial C_{O_{o}^{x}}(z, t)}{\partial z} \text { for } 0<z<l
$$

where $D_{c h e m}, \varepsilon_{L S C F}$ and $\tau_{L S C F}$ are related to the chemical diffusivity, the volume fraction and the tortuosity factor for the LSCF phase, respectively. The flux $J_{o}^{x}(z, t)$ is considered to be nil at the top of the electrode $(z=\ell)$ (condition used as the second boundary condition). The two last equations are combined in the mass balance for the oxygen in LSCF. In other words, the local variation in the flux is controlled by the kinetic rate of the oxygen exchange reaction together with a dynamic term related to the transient accumulation/depletion of oxygen in LSCF:

$$
\frac{\partial J_{O_{o}^{x}}(z, t)}{\partial z}=-v_{\text {chem }}(z, t)-\varepsilon_{L S C F} \frac{\partial C_{O_{o}^{x}}(z, t)}{\partial t} \text { for } 0<z<l
$$

The Faradaic current density is derived from the interfacial diffusion and it is calculated at the electrode/electrolyte interface as follows:

$$
\left.j_{e^{-}}(0, t)=2 F \frac{\varepsilon_{L S C F}}{\tau_{L S C F}} D_{c h e m} \frac{\partial C_{o_{o}^{x}}(z, t)}{\partial z}\right]_{z=0}
$$

By combining Eqs. (4-7) with the two boundary conditions, it is possible to derive an explicit semi-analytical solution for the CV response, expressed through the following equation [45]:

$$
j_{e^{-}}(t)=2 F C_{O_{o}^{x}}^{\max } \cdot \mathcal{L}^{-1}\left(\frac{1}{s \cdot M(s)}\right) * \frac{d h[\xi(t)]}{d t}
$$

where the symbol $(*)$ denotes the convolution product, $\mathcal{L}$ is the Laplace transform operator and $s$ is the Laplace variable. The term $M(s)$ is the so-called 'mass transfer function', defined as the ratio in the Laplace domain between the incremental changes of oxygen concentration 
and flux at the electrolyte interface $\left(M(s)=\mathcal{L} \Delta C_{O_{o}^{x}}(x=0, t) / \mathcal{L} \Delta J_{O_{o}^{x}}(x=0, t)\right)$. The term $h[\xi(t)]$ is referred as the potential-dependent function that depends on the controlledpotential technique $\left(h[\xi(t)]=\frac{1}{1+\exp (-\xi(t))}-\frac{1}{1+\exp \left(-\xi^{e q}\right)}\right)$.

In order to simplify the analyses, the electrochemical input parameters are replaced by dimensionless variables. In this approach, the chemical rate constant $k_{c h e m}$ and the electrode thickness $\ell_{L S C F}$ are respectively substituted by the dimensionless parameters $\lambda$ and $L$, as follows:

$$
\begin{gathered}
\lambda=\frac{S_{p}^{L S C F} k_{\text {chem }}}{2 f v \varepsilon_{L S C F}} \\
L=\ell_{L S C F}\left(\frac{2 f v}{D_{\text {chem }} / \tau_{L S C F}}\right)^{1 / 2}
\end{gathered}
$$

where $v$ is the imposed scan rate for the voltammetry computation and $f=F /(R T)$. In function of these two variables, it is possible to build the so-called 'zone diagram' as detailed in [45]. By imposing limit conditions on $\lambda$ and $L$, specific shapes of the cyclic voltammograms can be obtained with simplified closed-form expressions for the dimensionless current density. Moreover, the type of kinetic and/or mass transport control for the reaction is identified for each individual limiting zone. It is worth mentioning that the zone diagram reported in [45] is plotted for LSV starting in the cathodic direction for the special case where $\xi^{e q} \rightarrow \infty$. This hypothesis means that a full oxygen occupation in LSCF is reached at equilibrium (i.e. $\delta \rightarrow 0$ and $C_{O_{o}^{x}} \rightarrow C_{O_{o}^{x}}^{\max }$ ).

In order to investigate the impact of the Ohmic loss in the electrolyte on the CV response, the assumptions listed before have been taken into account to propose a numerical version of the ALS-based model. However, some slight differences have to be underlined. In the numerical version, the $\mathrm{CV}$ simulations have been performed starting at $\mathrm{OCP}$, corresponding to $\xi_{e q}=$ 4.896. Nevertheless, the condition $\xi^{e q} \rightarrow \infty$ is almost fulfilled, as the concentration of oxygen at OCP differs by less than $1 \%$ from the maximum concentration in LSCF in the chosen experimental conditions [47]. Moreover, the Nernst's equation at the electrode/electrolyte interface has been replaced with a fast and non-limiting reaction of ionic transfer (1a). In this condition, the expression of the oxygen concentration at the interface given in Eq. (2) is still satisfied. This alternative expression for Eq. (2) has been adopted in 
order to introduce in the model a description of the electrolyte. In this case, the oxygen migration in the electrolyte is modeled using a classical Ohm's law. This numerical version of the ALS-based model is referred as 'model-I' thereafter.

Elementary numerical model - The detailed description and validation of the elementary model are reported in [24]. A brief summary of the main characteristics is reported hereafter. In the same way as in model-I, this physically-based model considers an equivalent homogenous medium of the LSCF electrode. The reaction mechanism is decomposed into six elementary steps whose expressions are listed in Tab. I (Fig. 1c). In electrolysis mode, the bulk path is expressed as the ionic transfer at the LSCF/CGO interface (R1) followed by the excorporation reaction at the surface of the electrode particles (R2), while the surface path is defined as the direct oxidation at the TPBls (R3). Both pathways lead to the formation of charge species on the LSCF surface (R3). These oxygen ad-ions are firstly deionized (R4) to form neutral oxygen ad-atoms. Subsequently, these species can associate to produce dioxygen ad-molecules (R5) that are finally desorbed into the electrode porosities (R6). It is worth underlining that this elementary description of the reaction mechanism implies an electrostatic surface potential induced by the presence of holes in LSCF and oxygen ad-ions on the LSCF surface. As proposed in [43], this surface potential is assumed to affect the two reactions of charge transfers taking place on the electrode surface (excorporation R2 and deionization R4). Finally, all the expressions of kinetic rates along with the transport equations have been merged in a set of mass and charge balances written for each species in the electrode and electrolyte.

In contrast to the ALS-based model, it can be noticed that the charging/discharging effect of the double layer capacitance at the LSCF/CGO interface was taken into account. It must also be emphasized that the set of partial differential equations related to the mass and charge balances, developed in [24], are solved in the time domain by keeping the full nonlinearity of the system. Therefore, the model can be directly employed for the CV simulation. In this case, the difference in electronic potential at the top of the electrode, $\varphi_{e^{-}}\left(z=\ell_{L S C F}\right)$ and ionic potential in the electrolyte, $\varphi_{i o}\left(z=-\ell_{\text {electrolyte }}\right)$ (i.e. $\varphi_{e^{-}}\left(z=\ell_{L S C F}\right)-\varphi_{i o}(z=$ $\left.\left.-\ell_{\text {electrolyte }}\right) \approx-\varphi_{\text {io }}\left(z=-\ell_{\text {electrolyte }}\right)\right)$, varies with a triangular waveform starting from OCP: 


$$
\varphi_{\text {io }}\left(t, z=-\ell_{\text {electrolyte }}\right)=0 \pm w v(t)
$$

where $\ell_{\text {electrolyte }}$ is the electrolyte thickness. The term $w v(t)$ is the wave function, which depends on the chosen demi-amplitude $A$ and angular frequency $\omega$. The scan rate was changed in the simulation by varying the period $T_{\mathrm{w}}$ of the wave function $\left(\omega=2 \pi / T_{w}\right)$.

The simulations in [24] were carried out using the microstructural properties extracted from a 3D reconstruction of the tested electrode. The LSCF thermodynamic and transport properties were taken from the literature. The remaining input parameters, which consisted in the reaction kinetic constants, surface diffusivities and coverages of the adsorbed species at equilibrium (determined for $P_{O_{2}}=0.21 \mathrm{~atm}$ and then calculated for the other conditions), were determined by fitting the experimental polarizations curves at different operating temperatures. The model validation was then conducted by comparing the computed impedance diagrams with the experiments at OCP and under polarization. Moreover, as a further verification of the model reliability, the prediction given by the model for the evolution of the electrode polarization resistance at OCP with the oxygen partial pressure was also confronted with the experimental results. In both cases, the model has shown a very good agreement between the simulations and the experiments without any additional fitting. This result allowed considering the elementary model as a reliable representation of the LSCF electrochemical behavior. Therefore, this predictive model has been used in the present work without any adaption of the input parameters, knowing that the same type of LSCF electrode than the one used in [24] was used for the voltammetry measurements. It is referred as 'model-II' in what follows.

\section{Results and Discussion}

\subsection{Validation of model-II for the CV computation: effect of temperature and scan rate}

The capability of the full elementary model (model-II) to predict the voltammograms has been checked by comparing the simulated and experimental curves as functions of the operating temperature and the applied scan rate. As previously mentioned, all the computations have been carried out using the input data reported in [24]. Nevertheless, for the present CV simulations, the Ohmic loss in the CGO barrier has been neglected because of its low thickness $(2 \mu \mathrm{m})$ and only the $8 \mathrm{YSZ}$ electrolyte has been considered with an ionic 
conductivity equal to $2.3 \mathrm{~S} \cdot \mathrm{m}^{-1}$ and $1.4 \mathrm{~S} \cdot \mathrm{m}^{-1}$ at $700{ }^{\circ} \mathrm{C}$ and $650{ }^{\circ} \mathrm{C}$, respectively (data provided by the electrolyte supplier $\mathrm{Kerafol}^{\circledR}$ ). Besides, since the measurements were performed using a three-electrode setup in a symmetrical cell configuration, the electrolyte thickness $\ell_{\text {electrolyte }}$ in the simulation has been chosen to the half of the whole electrolyte thickness, leading to $\ell_{\text {electrolyte }}=125 \mu \mathrm{m}$ [48]. Moreover, the contact resistance $R_{\text {contact }}$ between the platinum grids (used as current collectors) and the electrode surface has been also considered in the model as an additional Ohmic loss. The value of $R_{\text {contact }}$ was determined from the experimental impedance diagrams recorded at OCP. It was obtained by subtracting the electrolyte resistance $R_{\text {electrolyte }}$ from the series resistance $R_{S}$ measured as the intercept of the impedance diagram with the real axis, at high frequency in the Nyquist plot: $R_{\text {contact }}=$ $R_{S}-R_{\text {electrolyte }}$. This contact resistance has been found to increase from $R_{\text {contact }}=0.96 \Omega$. $\mathrm{cm}^{2}$ to $R_{\text {contact }}=1.82 \Omega \cdot \mathrm{cm}^{2}$, by decreasing the temperature from $700{ }^{\circ} \mathrm{C}$ down to $650{ }^{\circ} \mathrm{C}$. This temperature dependence of $R_{\text {contact }}$, which has been already reported by other authors [49], could be explained by a higher viscoplastic accommodation of the metallic grids at higher temperatures.

Regarding the effect of the temperature on the CV response, the voltammograms recorded at $700{ }^{\circ} \mathrm{C}$ and $650{ }^{\circ} \mathrm{C}$ for an oxygen partial pressure of $0.1 \mathrm{~atm}$ are shown in Fig. 2. This oxygen partial pressure, slightly lower than the atmospheric condition, was chosen to enhance the hysteresis in the voltammograms. Indeed, it was shown in our previous experimental work performed at lower temperature [34] that the hysteresis is more pronounced at low $P_{O_{2}}$. However, whatever the temperature and the scan rate, the hysteresis remains rather limited at oxygen partial pressures close to $P_{O_{2}}=0.21$ atm, as already reported for LSCF electrodes [32, $50,51]$. The comparison between the experimental data and the curves simulated with modelII is also reported in Fig. 2. It can be seen that the model is able to reproduce quite correctly the general shape of the voltammograms at both operating temperatures. As for the experiments, a slightly higher hysteresis is found at $650{ }^{\circ} \mathrm{C}$ with the model.

As a further element of validation, the model capability to capture the evolution of the CV response when changing the potential scan rate has been investigated. The experimental measurements have been conducted by varying the scan rate from $20 \mathrm{mV} \cdot \mathrm{s}^{-1}$ up to 1000 
$\mathrm{mV} \cdot \mathrm{s}^{-1}$, at the operating temperature of $650{ }^{\circ} \mathrm{C}$ and $P_{O_{2}}=0.1$ atm (Fig. 3a and 3c). As expected, the hysteresis increases with the scan rate as classically observed in $\mathrm{CV}$ experiments [52]. This sensitivity of the CV response with the scan rate would be mainly explained by the slow diffusional process for the oxygen vacancies transport in LSCF material as mentioned in [32]. It is worth noting that the model is able to retrieve quite precisely the evolution of the $\mathrm{CV}$ response with the scan rate (Fig. 3b and 3d). To conclude, it has been shown that the computed voltammograms with model-II are quite in good agreement with the experimental curves obtained under various operating conditions. Since all these results were obtained without fitting, model-II can be considered as validated to predict the $\mathrm{CV}$ response of the LSCF electrode. It should be noted that this model was extensively validated on a large experimental dataset recorded from i-V curves and EIS diagrams in [24]. Therefore, it will be used as a reliable tool to predict the LSCF electrode behavior hereafter.

\subsection{Calibration of model-I}

The implemented numerical version of the ALS-based model (model-I) has been calibrated using simulations obtained with the full elementary model (model-II). The input parameters used for model-I are reported in Table II. The microstructural parameters and thermodynamic data correspond to the ones taken for the elementary model. As mentioned in section 2.2, the kinetic constant of the ionic transfer R1 has been considered as not limiting, in order to fulfill the boundary condition of a quasi-equilibrium state at the electrode/electrolyte interface. Therefore, the chemical rate constant $k_{c h e m}$ for the global oxygen exchange between LSCF and gas remains the only unknown parameter. This parameter has been determined, by fitting with model-I, the impedance diagram obtained at $\mathrm{OCP}, 700{ }^{\circ} \mathrm{C}$ and $P_{O_{2}}=0.1 \mathrm{~atm}$, using model-II (Fig. 4a). As reported in Table II, a value of $1.23 \cdot 10^{-7} \mathrm{~m} \cdot \mathrm{s}^{-1}$ has been obtained in these conditions. It can be noticed that the computed impedance diagrams present the same polarization resistance $R_{\text {pol }}$ and a quite good match in terms of shape, especially at high frequencies. As expected, the diagram related to model-I is a perfect Gerischer element as predicted by the ALS-based model. On the other hand, the one simulated with the full elementary model is slightly depressed, due to the more complex reaction mechanism, which better reflects the real behavior of the LSCF electrode. However, despite the good superposition of the impedance diagrams, it can be noticed in Fig. $4 \mathrm{~b}$ that the consistency between the two i-V curves, corrected from the Ohmic drop, is valid only near OCP. Indeed, 
it diverges highly for anodic potentials since a limiting current is evidenced for model-I. This behavior is linked to the fact that the ALS-based approach neglects the contribution of the surface path in the reaction mechanism, which has been demonstrated to be the dominant pathway for the LSCF electrode under SOEC mode [21, 22, 24]. From this point of view, the electrode modelling under polarization requires a more detailed description of the reaction mechanism that is not taken into account in the ALS-based approach.

\subsection{Comparison between model-I and model-II for the $\mathrm{CV}$ response}

\subsubsection{Microstructural effect: from a porous to a quasi-dense electrode}

As the electrode microstructural parameters play a significant role on experimental CV curves [34], their effect on the voltammetry response have been investigated with both models at 700 ${ }^{\circ} \mathrm{C}$ and $P_{O_{2}}=0.1 \mathrm{~atm}$. In this first part of the study, it is worth emphasizing that the Ohmic losses due to the electrolyte and the contact resistances have been neglected by considering $\ell_{\text {electrolye }} \rightarrow 0$ and $R_{\text {contact }} \rightarrow 0$. The analysis has been performed by starting from the classical porous electrode used for the model validation with a scan rate of $100 \mathrm{mV} \cdot \mathrm{s}^{-1}$ (i). The procedure has consisted to simulate the additive effects of four successive steps: division of the specific electrode surface area by a factor of 10 (ii), increase of the LSCF volume fraction up to $90 \%$ (iii), reduction of the electrode thickness from $35 \mu \mathrm{m}$ down to $5 \mu \mathrm{m}$ (iv), and finally, lowering the scan rate down to $1 \mathrm{mV} \cdot \mathrm{s}^{-1}(\mathrm{v})$. The first four conditions have allowed passing from the case of a porous 'thick' electrode to a quasi-dense 'thin' film, while the last step has allowed investigating the electrode response in a quasi-steady state regime. The CV curves obtained at each step of the procedure have been interpreted through the zone diagram established in [45].

For model-I, the trajectory in the zone diagram can be predicted using Eqs. (9a) and (9b) as shown in Fig. 5a. The solid circles on this trajectory correspond to each step of the procedure. For the standard 'thick' porous electrode, the voltammogram falls in zone 3 (blue curve), indicating that the $\mathrm{CV}$ response is controlled by both the chemical reaction of oxygen exchange and the oxygen diffusion in LSCF under semi-infinite conditions as detailed in [45]. Both the decrease of the specific surface area of LSCF $S_{p}^{L S C F}$ (orange curve) and the increase of the volume fraction of LSCF $\varepsilon_{L S C F}$ (green curve) yield a horizontal translation to the left in zone 3 since the dimensionless parameter $\lambda$ is lowered (Eq. (9a)). As expected when the electrode is getting dense (i.e. $\varepsilon_{L S C F}$ is increased and $S_{p}^{L S C F}$ is decreased), the effect of the 
chemical process decreases up to reach a response with no chemical effect and only a control by diffusion in a semi-infinite medium (translation in zone $1 \cap 3$ for an even a denser electrode). Subsequently, the decrease of the electrode thickness $\ell_{L S C F}$ (yellow curve) yields a vertical translation due to the decrease of the dimensionless thickness $L$, according to Eq. (9b). Consequently, the voltammograms move towards zone 4 as shown by the more symmetrical shape of the CV curve in Fig. 5a (yellow curve). In this zone, the CV response is governed by both the chemical oxygen exchange and the diffusion in a finite medium as expected for a thin film [45]. Finally, the decrease of the scan rate down to $1 \mathrm{mV} \cdot \mathrm{s}^{-1}$ (purple curve) shifts the response at the intersection of zone 4 and zone $2 \cap 4$. The resulting curve, whose enlargement is reported in the corner of Fig. 5a, corresponds to an almost steady-state condition with a sigmoidal shape. All the reported results are in quite good agreement with the semi-analytical solutions determined by Montella et al. [45], ensuring the reliability of this implemented numerical version (model-I). The comparison between model-I and the semianalytical solution is detailed in the supplementary document (Fig. S1).

The same study has been performed with the elementary model (model-II). The corresponding $\mathrm{CV}$ curves are reported in Fig. 5b. It can be seen that this model does not change significantly the shape of the $\mathrm{CV}$ response. Therefore, it can be proposed that the zone diagram can still be used to analyze the results. Visual analysis shows that the CV curves obtained with model-II are only translated to the left in the zone diagram with respect to model-I. The value of this shift, $\Delta \log \lambda$, was estimated considering the purple curves, plotted at $1 \mathrm{mV}$. $\mathrm{s}^{-1}$, in Fig. 5a and $5 \mathrm{~b}$, as their shape is highly modified from model-I to model-II. For this purpose, the voltammograms obtained with model-II has been roughly retrieved with the semi-analytical solution (knowing the voltammograms obtained with this model are quite well representative of those obtained with the elementary description as pointed out in the next section). The detail of this analysis is reported in the supplementary (Fig. S2 and S3). The translation on the $\mathrm{x}$-axis in the zone diagram was found to be almost equal to $\Delta \log \lambda=-1.6$. The corresponding points, related to this translation, are represented by empty circles in Fig. 5b. Thanks to this positioning, it can be noticed that, for each circles, the global shape of the simulated voltammograms is well consistent with the one reported in the zone diagram. Therefore, for the standard case (blue curve), it is found that the voltammogram drops in the left part of zone 3 , in a region very close to zone $1 \cap 3$. As expected, the decrease of $S_{p}^{L S C F}$ (orange curve) yields to move the $\mathrm{CV}$ curve at the intersection of zone 1 and zone $1 \cap 3$ of the diagram, where the voltammogram is only slightly impacted by the decrease of the effective chemical 
constant. This result would thus confirm that the CV response is positioned in the left part of the zone diagram with no effect of the global reaction of oxygen exchange (including in this model several elementary steps). After increasing $\varepsilon_{L S C F}$ (green curve), the CV curve is only slightly translated horizontally to the left. When $\ell_{L S C F}$ is decreased (yellow curve), the voltammogram is translated vertically in zone 1 near zone $1 \cap 4$, as suggested by the limiting current falling to zero. This localization of the voltammetry curve for the quasi-dense thin film means that the $\mathrm{CV}$ response is characteristics of a uniform insertion reaction with no chemical reaction effect. Finally, the decrease of the scan rate shifts the CV response to zone 4 as shown by the purple peak shaped-curve in the corner of Fig. 5b, indicating an increase of the chemical reaction effect.

In summary, the results of Fig. 5 allows suggesting that:

(i) The simulated voltammograms with model-II, which are representative of the real behavior of the LSCF electrode, are consistent with the ones predicted by model-I, keeping in mind that the surface path is neglected in this ALS-based model (cf. section 3.2). This statement indicates that the semi-analytical solution and the corresponding zone diagram must provide a rather good estimation of the CV response for the LSCF electrode when the Ohmic losses are negligible. Thus, in the investigated conditions of the study, the attached species on the LSCF surface along with the gaseous oxygen in the porosity are not likely to play a major role in the CV response. This remark suggests that the $\mathrm{CV}$ behavior is mainly controlled by the transient accumulation or depletion of oxygen vacancies in LSCF as already pointed out in [34].

(ii) The positions in the zone diagram of the voltammograms obtained with model-I are shifted to the right compared to those obtained with the elementary model (model-II). As shown in Fig. 5a and 5b, it seems that a simple translation along the $\mathrm{x}$-axis in the zone diagram is sufficient to recover the results of model-II. We can therefore suggest that the shift between the two models could come from a too large value of $\log \lambda$ and thus from an overestimation of $k_{\text {chem }}$. Indeed, the value of $k_{c h e m}$ in model-I was determined using impedance spectra at OCP, while the accuracy of the i-V curves fitting under dc current was ignored (cf. Fig. 4). In order to improve the match of the polarization curves under cathodic dc current, the value of $k_{c h e m}$ was determined by fitting the cathodic polarization curve, as shown in Fig. S4 of the supplementary document. One must remind that the discrepancy for the anodic polarizations can be related to the contribution of the dominant surface path in the reaction mechanism 
under SOEC mode. With this new fitting procedure, a lower value of $k_{c h e m}$ has been obtained: typically, it is equal to $3.0 \cdot 10^{-8} \mathrm{~m} \cdot \mathrm{s}^{-1}$ when the parameter is determined in the potential range from 0 to $-0.1 \mathrm{~V}$ (this value is 4 times lower than the one determined from the fitting of the impedance diagram at OCP). The analysis to mimic the passage from a porous standard electrode to a quasi-dense film has been then repeated with model-I. As expected, the lower value of the kinetic constant has shifted the electrode response on the left in the zone diagram with a $\mathrm{CV}$ response closer to the one found with the elementary model (Fig. S5). With the same hypothesis considering a translation on the $\mathrm{x}$ axis, the shift in the zone diagram has been estimated to $\Delta \log \lambda=-0.6$. For a perfect agreement between the two models, a lower value of $k_{\text {chem }}$ would be thus necessary. This lower value could be obtained by fitting the polarization curves on a larger range of cathodic polarizations. Nevertheless, these results confirm that the difference between the two models is mostly related to an overestimation of $k_{\text {chem }}$. Therefore, as long as the Ohmic losses can be neglected, the semi-analytical model developed in our previous work [45] can be used to analyze the $\mathrm{CV}$ response of the LSCF electrode. For this purpose, the chemical constant must be determined on the cathodic polarization curve and not only at OCP.

\subsubsection{Cyclic voltammetry peaks evolution}

The evolution of the voltammetry peaks has been investigated as a further comparison between the two models. In the ALS-based model (model-I), this evolution is determined by theoretical expressions that link the peak coordinates with the model input parameters. For instance, the current density for the cathodic peak $j_{\mathrm{pc}}$ in zone $1 \cap 3$ is expressed as followed [45]:

$$
j_{p c}^{\text {model-I }}=-0.4463 \times 2 F C_{O_{o}^{x}}^{\max } \varepsilon_{L S C F}\left(2 f v \frac{D_{c h e m}}{\tau_{L S C F}}\right)^{1 / 2}
$$

This zone was selected as it corresponds to the behavior classically observed for the reversible electron transfer reaction with diffusion of the electroactive species in a planar semi-infinite medium [52]. This theoretical evolution of $j_{p c}$ with the oxygen chemical diffusivity has been compared to the simulated data obtained with the elementary model (model-II) when the voltammograms is located in zone $1 \cap 3$. It means that we started from the orange curve in 
Fig. $5 b$, located in zone 1 near zone $1 \cap 3$ and that we decreased the value of $D_{\text {chem }}$ in order to rapidly enter in zone $1 \cap 3$. As it can be seen in Fig. 6a, the peak current simulated with model-II evolves quite perfectly with the square root of the chemical diffusivity $D_{\text {chem }}$ as predicted by Eq. (11). Indeed, the following expression has been fitted on the simulated data:

$$
j_{p c}^{\text {model-II }}=-0.4200 \times 2 \cdot F C_{O_{o}^{x}}^{\max } \varepsilon_{L S C F}\left(2 f v \frac{D_{\text {chem }}}{\tau_{L S C F}}\right)^{1 / 2}
$$

The numerical pre-factor identified with model-II for $j_{p c}^{\text {model-II }}$ is almost the same than the one in Eq. (11). This slight discrepancy between both slopes could come from the fact that the assumption $\xi^{e q} \rightarrow \infty$ used for establishing Eq. (11) is not fulfilled when $E_{e q}$ is taken to zero in the numerical implementation of the two models (cf. section 2.2). Indeed, $\xi^{e q}=4.896$ results in a slightly lower value of the coefficient 0.4463 , as shown by the simulations in the supplementary document of our previous work [45] (see page 37, Fig. I.9).

In order to confirm the consistency between the two models, the CV response obtained with model-I has also been compared to the voltammogram simulated with the full elementary model (model-II) when both are calculated in the same $1 \cap 3$ zone. It can be shown in Fig. $6 \mathrm{~b}$ that the two types of voltammograms are almost superimposed since they are independent on $k_{\text {chem }}$ in this zone. The current densities of the peaks are especially quite identical. This result reinforces the claim that the CV behavior for the LSCF material is practically only governed by the transient evolution of the oxygen under-stoichiometry (without a significant impact of the other species taken into account in model-II). This change in the oxygen vacancies in the material is obviously controlled by the fast ionic transfer at the electrolyte interface, the solidstate diffusion within the electrode thickness and the rate of oxygen exchange with the gas phase [21, 24].

\subsubsection{Impact of the Ohmic losses}

The same approach as in section 3.3.1 has been repeated by taking into account the electrolyte thickness $\ell_{\text {electrolyte }}=125 \mu \mathrm{m}$ and the contact resistance $R_{\text {contact }}=0.96 \Omega . \mathrm{cm}^{2}$, at $700{ }^{\circ} \mathrm{C}$ and $P_{O_{2}}=0.1 \mathrm{~atm}$. This study was carried out to evaluate the effect of the Ohmic losses on the $\mathrm{CV}$ response with the two models. From Fig. 7, it can be observed that the addition of the electrolyte and contact resistances in the models results in a complete distortion of the voltammograms. These simulations are obviously coherent with the experimental data 
reported in Fig. 2 and Fig. 3. Therefore, the information related to the voltammetry peaks is completely lost especially under cathodic polarization. This statement is in good agreement with the conclusion reported by Tezyk et al. [34]. Indeed, the authors have suggested that the Ohmic drop is a major limitation for the interpretation of CV experiments. Indeed, it cannot be compensated accurately because of variation of the series resistance with the polarization, meaning that the Ohmic drop compensation function of the classical electrochemical equipment is not efficient.

From the comparison of the voltammograms obtained with the two models (Fig. 7a and 7b), it can be noticed that the global shape is quite similar except for the quasi-dense thin film simulated at a low scan rate (purple curves). In this case, one cathodic peak and a reverse anodic one are detected on the voltammogram simulated with model-II, whereas the curve obtained with model-I exhibits no peak (Fig. 7a and 7b). It is worth noting that the curve obtained with the full elementary model is consistent with the results reported by Tezyk et al. [34] on a quasi-dense LSCF thin electrode deposited by Electrostatic Spray Deposition (ESD). Indeed, two voltammetry peaks were observed in this condition in contrast to the curves obtained for a more classical 'thick' porous LSCF electrode deposited by screen-printing. Therefore, this result also participates to highlight the reliability of the elementary model to predict accurately the $\mathrm{CV}$ curves. It can be noticed that the peak shaped voltammogram for the quasi-dense 'thin' film obtained with model-II is located in zone 4 (Fig. 7b). Regarding model-I, the absence of peaks in the voltammogram confirms that the chemical constant fitted on the impedance diagram at OCP is overestimated as already mentioned. Indeed, the voltammogram obtained with this model without Ohmic losses is located near the shaded area of the zone diagram, corresponding to a sigmoidal shape of the CV response. It is worth emphasizing that it has been checked that the absence of limiting current density under catholic polarization is due to the use of too low voltage amplitude A for the simulation. Moreover, as the voltammogram is shifted to the left toward the zone 4 with the second model calibration (i.e. $k_{\text {chem }}=3.0 \cdot 10^{-8} \mathrm{~m} \cdot \mathrm{s}^{-1}$ ), the simulations have confirmed that the anodic and cathodic peaks start to appear in the CV response (Fig. S6 reported in the supplementary).

Since the Ohmic losses are the major limitation for the interpretation of the CV experiments, a sensitivity analysis has been carried out with model-II by changing the electrolyte thickness. The study has been performed considering the standard porous electrode by imposing two 
scan rates of $100 \mathrm{mV} \cdot \mathrm{s}^{-1}$ and $5 \mathrm{mV} \cdot \mathrm{s}^{-1}$. For the sake of clarity, the contact resistance has also been set to zero $\left(R_{\text {contact }} \rightarrow 0\right)$. As shown in Fig. 8, we observe the existence of a quasiinvariant point during the reverse scan whatever the scan rate. As expected, the dependency of the voltammograms with the Ohmic loss is less pronounced at low scan rate, due to lower current density values. For instance, the cathodic and reverse anodic peaks start to be detected for an electrolyte thickness of around $10 \mu \mathrm{m}$ at $5 \mathrm{mV} \cdot \mathrm{s}^{-1}$ whereas, in this condition, the voltammogram is still strongly distorted at $100 \mathrm{mV} \cdot \mathrm{s}^{-1}$. Therefore, as expected, there is an optimum in terms of scan rate to detect the voltammetry peaks. Nevertheless, even at low scan rate, an electrolyte thickness of less than $10 \mu \mathrm{m}$ is required to observe well-defined anodic and cathodic peaks. This statement demonstrates that, even with a very thin electrolyte without contact resistance, the CV measurements can be still strongly affected by the Ohmic losses. Therefore, in the operating conditions of the SOCs technology, there is no realistic experimental configuration that would allow avoiding this artifact for a clear highlight of the voltammetry peaks (i.e. by using the classical three-electrode setup since the electrolyte thickness is at least equal to $100 \mu \mathrm{m})$.

To overcome the problem of the ohmic drop compensation, the data analyses with a numerical tool could be a relevant strategy for studying the CV response of LSCF. Indeed, as done previously, the modelling approach can be used to deconvoluate the effect of the Ohmic losses from the experimental voltammograms. For this purpose, after the prior model calibration on the experimental $\mathrm{CV}$ curves, the simulation just needs to be run a second time without the Ohmic losses. As an illustration of the applied methodology, the simulated voltammograms computed in the standard case in Fig. S5 with model-I and in Fig. 5b with model-II (porous electrode without electrolyte at $700^{\circ} \mathrm{C}$ and $P_{O_{2}}=0.1 \mathrm{~atm}$ ) correspond to the simulation of the experimental data reported in Fig. $2 b$ (with the Ohmic losses). For this 'data post-processing', model-I, which is much easier to implement than model-II, can be used since it provides a rather good approximation of the $\mathrm{CV}$ response. Before this processing, it is obvious that the electrolyte resistance must be determined accurately at OCP with twoelectrode measurements.

\subsubsection{Impact of the LSCF demixing on the cyclic voltammetry response}

The impact of the LSCF decomposition on the CV response has been investigated with the elementary model (model-II) without electrolyte. The analysis has been conducted 
considering the classical porous electrode as the standard case numerically tested at 700 ${ }^{\circ} \mathrm{C}, P_{O_{2}}=0.1 \mathrm{~atm}, \mathrm{~A}=0.5 \mathrm{~V}$ and $v=100 \mathrm{mV} \cdot \mathrm{s}^{-1}$. To mimic the impact of the surface passivation and the loss of ionic conductivity, the electrode specific surface area $S_{p}^{L S C F}$ and the oxygen chemical diffusion coefficient $D_{\text {chem }}$ have been respectively decreased up to $50 \%$ of their original values. This evolution can be seen as an upper bound for the material degradation as discussed in [24]. The simulated cyclic voltammograms have been interpreted in the frame of the zone diagram. As mentioned above, the CV curve for the standard case falls in proximity of zone $1 \cap 3$ (Fig. 5b). In this zone, the electrode behavior is mainly controlled by the oxygen diffusion with no effect of the global reaction of oxygen exchange. Therefore, no evolution in the CV curves has been found when decreasing $S_{p}^{L S C F}$ (Fig. 9a). To highlight the impact of this microstructural parameter, the scan rate was lowered down to 5 $\mathrm{mV} \cdot \mathrm{s}^{-1}$ to shift the $\mathrm{CV}$ response in a zone where the electrode behavior is controlled by the reaction of oxygen exchange with the gas phase. In this condition, the effect of the surface passivation is clearly shown in Fig. 9b. According to the shape of the voltammograms in this figure, the $\mathrm{CV}$ behavior would be located in zone 4 of the diagram (this new location is explained since the decrease of the scan rate induces an increase of $\lambda$ and a decrease of $L$ : cf. Eq. 9a and 9b). Moreover, it is found that the limiting current density under cathodic polarization is decreased by decreasing the electrode specific surface area, as expected from the analytical solution (indeed, this evolution is due to the progressive displacement to the left in the zone diagram when $S_{p}^{L S C F}$ is decreased).

Considering the loss of ionic conductivity, the voltammograms are substantially affected by the decrease of $D_{\text {chem }}$ (Fig. 9c). Indeed, the voltammetry curve depends only on the oxygen solid-state diffusion in LSCF in zone $1 \cap 3$ for the standard case. Moreover, the current density for the cathodic peak is increased with $D_{c h e m}$, in agreement with Eq. (12).

Once the Ohmic losses have been subtracted, it appears from the present study that the LSCF decomposition can be potentially detected using the cyclic voltammetry (at least after substantial material degradation). The analysis of the variation of the CV curves would thus provide useful insights on the effect of LSCF demixing on both the surface passivation and the change in the material properties. From a qualitative point of view, the existence of a limiting current density under cathodic polarization for peak shaped voltammograms will suggest an increase of the chemical reaction effect meaning that a mixed chemical-kinetic and diffusion control should be anticipated. It is worth mentioning that a variation of the oxygen 
chemical diffusivity will affect the magnitude of the polarization resistance without any significant modification of the shape of EIS diagrams [24]. From transient cyclic voltammetry, one can expect a variation of dissymmetry between cathodic and anodic peaks (see Fig. 5). Moreover, CV measurements are not sensitive to the cell symmetry and no artifacts could be anticipated as compared to impedance measurements [53]. For these reasons, cyclic voltammetry can give a new insight on the characterization of LSCF-based electrodes under operating conditions.

\section{Conclusion}

Two numerical models have been developed to simulate the cyclic voltammetry of LSCF porous electrode. The first one (model-I) takes into account the solid-state diffusion in LSCF coupled with a global reaction of oxygen exchange with the gas phase while the ionic transfer at the electrode/electrolyte interface is considered at equilibrium. It corresponds to a numerical version of a semi-analytical solution for the voltammetry response recently proposed for this type of mixed conducting electrode. The second one (model-II) is based on a description of the reaction mechanism in a sequence of pure elementary steps. It has been adapted from a previous version that was already validated on impedance spectra and polarization curves.

The relevance of the elementary model to predict the voltammograms has been checked using experimental data obtained by testing a symmetrical LSCF cell in a three-electrode set-up at different operating temperatures and scan rates. The good agreement between the measurements and the simulations has allowed validating the model capability to predict accurately the $\mathrm{CV}$ response.

A first sensitivity analysis has been performed with the two models by neglecting the Ohmic losses in the computation of the cyclic voltammetry at $700{ }^{\circ} \mathrm{C}$ and $P_{O_{2}}=0.1 \mathrm{~atm}$. In this study, the microstructural properties and the thickness of the electrode have been changed one after the other to pass from a classical porous electrode to a thin quasi-dense LSCF film. The results have been interpreted in the frame of the so-called zone diagram method. It has been found that the voltammograms obtained with the two models are very similar if the chemical 
constant is determined on the cathodic polarization curve and not only at OCP. Therefore, in this condition and when the Ohmic losses are negligible, the simplified model (model-I) can provide a satisfactory approximation of the CV curves for the LSCF electrode. This result confirms that the CV behavior of the LSCF material is mainly governed by the transient evolution of the oxygen content in LSFC. This evolution is mainly controlled by the solidstate diffusion within the electrode along with the chemical oxygen exchange with the gas phase taken into account in model-I.

The same study for porous and quasi-dense electrodes has been repeated taking into account the Ohmic losses in the simulations. It has been shown that they induce a strong distortion of the voltammograms making their interpretation impossible in practice. In this frame, it has been established that an electrolyte thickness as low as $10 \mu \mathrm{m}$ is needed to reveal the voltammetry peaks at low scan rates (without any contact resistance). To overcome this issue, a methodology using the modelling approach has been proposed. It consists in the postprocessing of experimental data with the simplified model (model-I) to remove the Ohmic losses and thus highlight the voltammetry peaks, once the electrolyte resistance was accurately determined.

Finally, the impact of the LSCF decomposition on the CV response has been assessed with model-II. Both the surface passivation and decrease of the chemical diffusivity have been found to change significantly the voltammograms. Therefore, this technique can be seen as an additionnal experimental approach to characterize MIEC electrodes under operation.

\section{Acknowledgements}

This project has received funding from the Fuel Cells and Hydrogen 2 Joint Undertaking (JU) under grant agreement $n^{\circ} 825027$ (AD ASTRA project). The JU receives support from the European Union's Horizon 2020 research and innovation program and Denmark, France, Italy, Spain, Poland, Netherlands, Greece, Finland, Estonia, Germany, United Kingdom, Switzerland. The work has also been partially supported by the Carnot Institutes (CASSIOPEE project) and Genvia company. 


\section{List of Symbols}

\section{Roman Symbols:}

A

$C_{O_{0}^{x}}^{\max }$

$C_{V_{0}^{*}}$

$C_{V_{o}^{*}}^{e q}$

$D_{\text {chem }}$

E

F

$h^{\circ}$

$j_{e^{-}}$

$J_{o}^{x}$

$k_{\text {chem }}$

$k_{+}$

$\mathcal{L}$

$\lambda_{L S C F}$

$\lambda_{\text {CGO }}$

$\ell_{Y S Z}$

$M(s)$

$O_{o}^{X}(L S C F)$

$O_{o}^{X}(C G O)$

$O^{-}-S_{L S C F}$

$O-S_{L S C F}$

$\mathrm{O}_{2}-S_{L S C F}$

$\mathrm{O}_{2}$

$P_{O_{2}}$

$R$

$R_{S}$

$R_{p}$

$R_{\text {contact }}$

$R_{\text {electrolyte }}$

$S$

$S_{L S C F}$

$S_{p}^{L S C F / g a s}$

$T$

$T_{\mathrm{w}}$

$V_{o}^{*}(L S C F)$

$V_{o}^{\circ}(C G O)$
Wave amplitude

Maximum concentration of neutral oxygen atoms in LSCF

Vacancies concentration in LSCF

Vacancies concentration in LSCF at equilibrium

Bulk oxygen chemical diffusion coefficient in LSCF

Local electrode potential

Faraday's constant

Hole defect in LSCF

Faradaic current density

Flux of oxygen in the LSCF bulk

Chemical kinetic constant

Ionic transfer kinetic constant

Laplace transform operator

Electrode thickness

CGO electrolyte thickness

YSZ electrolyte thickness

Mass transfer function

Oxygen atom in the LSCF lattice

Oxygen atom in the CGO lattice

Oxygen ad-ion on LSCF surface

Oxygen ad-atom on LSCF surface

Oxygen ad-molecule on LSCF surface

Gaseous oxygen molecule

Oxygen partial pressure

Universal gas constant

Series resistance

Polarization resistance

Contact resistance

Electrolyte resistance

Laplace variable

Adsorption site on LSCF surface

Specific surface area between LSCF and gas phase

Absolute temperature or Wave period

Wave function period

Oxygen vacancy in the LSCF lattice

Oxygen vacancy in the CGO lattice
(V)

$\left(\mathrm{mol} \mathrm{m}^{-3}\right)$

$\left(\mathrm{mol} \mathrm{m}^{-3}\right)$

$\left(\mathrm{mol} \mathrm{m}^{-3}\right)$

$\left(\mathrm{m}^{2} \mathrm{~s}^{-1}\right)$

(V)

$\left(\mathrm{C} \mathrm{mol}{ }^{-1}\right)$

$(-)$

$\left(\mathrm{A} \mathrm{m}^{-2}\right)$

$\left(\mathrm{mol} \cdot \mathrm{m}^{-2} \cdot \mathrm{s}^{-1}\right)$

$\left(\mathrm{m} \cdot \mathrm{s}^{-1}\right)$

$\left(\mathrm{mol} \cdot \mathrm{m}^{-1} \cdot \mathrm{s}^{-1}\right)$

$\left(\mathrm{s}^{-1}\right)$

$(\mu \mathrm{m})$

$(\mu \mathrm{m})$

$(\mu \mathrm{m})$

$\left(\mathrm{s} \mathrm{m}^{-1}\right)$

$(-)$

$(-)$

$(-)$

$(-)$

$(-)$

$(-)$

(atm)

$\left(\mathrm{J} \mathrm{mol}^{-1} \mathrm{~K}^{-1}\right)$

$\Omega \mathrm{cm}^{2}$

$\Omega \mathrm{cm}^{2}$

$\Omega \mathrm{cm}^{2}$

$\Omega \mathrm{cm}^{2}$

$(-)$

$(-)$

$\left(\mathrm{m}^{-1}\right)$

(K) or (s)

(s)

$(-)$

$(-)$

\section{Greek Symbols:}

$\alpha$

$\varepsilon_{L S C F}$

$v$
Charge transfer coefficient

Phase volume fraction for the phase $\mathrm{X}$

Potential scan rate
(-)

$(-)$

$\left(\mathrm{V} \mathrm{s}^{-1}\right.$ ) 


$\begin{array}{lll}\xi & \text { Dimensionless electrode potential } & (-) \\ \pi & \text { Pi constant } & (-) \\ \sigma_{Y S Z} & \text { Ionic conductivity of YSZ } & \left(\mathrm{S} \cdot \mathrm{m}^{-1}\right) \\ \varphi_{i} & \text { Potential } & (\mathrm{V}) \\ \tau_{L S C F} & \text { Tortuosity factor for the phase X } & (-) \\ \omega & \text { Angular frequency } & \left(\mathrm{rad} \mathrm{s}^{-1}\right)\end{array}$

\section{List of Abbreviations}

$\begin{array}{ll}\text { CE } & \text { Counter Electrode } \\ \text { CGO } & \text { Ceria doped Gadolinium Oxide } \\ \text { CV } & \text { Cyclic Voltammetry } \\ \text { EIS } & \text { Electrochemical Impedance Spectroscopy } \\ \text { LSCF } & \text { Lanthanum Strontium Cobalt Ferrite } \\ \text { LSV } & \text { Linear Sweep Voltammetry } \\ \text { MIEC } & \text { Mixed Ionic and Electronic Conductor } \\ \text { OER } & \text { Oxygen Electrode Reaction } \\ \text { OCP } & \text { Open Circuit Potential } \\ \text { RE } & \text { Reference Electrode } \\ \text { SOC } & \text { Solid Oxide Cells } \\ \text { SOFC } & \text { Solid Oxide Fuel Cell } \\ \text { SOEC } & \text { Solid Oxide Electrolysis Cell } \\ \text { TPBls } & \text { Triple Phase Boundary lengths } \\ \text { WE } & \text { Working Electrode } \\ \text { YSZ } & \text { Yttria Stabilized Zirconia }\end{array}$




\section{References}

[1] Hauch A., Küngas R., Blennow P., Hansen A. B., Hansen J. B., Mathiesen B. V., and M. B. Mogensen. "Recent Advances in Solid Oxide Cell Technology for Electrolysis." Science 370, no. 6513 (October 9, 2020): eaba6118.

https://doi.org/10.1126/science.aba6118.

[2] Lyu Y., Xie J., Wang D., and Wang J. "Review of Cell Performance in Solid Oxide Fuel Cells.” Journal of Materials Science 55, no. 17 (June 2020): 71847207.https://doi.org/10.1007/s10853-020-04497-7.

[3] Monaco F., Hubert M., Vulliet J., Ouweltjes J. P., Montinaro D., Cloetens P., Piccardo P., Lefebvre-Joud F., Laurencin J. "Degradation of Ni-YSZ Electrodes in Solid Oxide Cells: Impact of Polarization and Initial Microstructure on the Ni Evolution." Journal of The Electrochemical Society 166, no. 15 (2019): https://doi.org/10.1149/2.1261915jes.

[4] Hubert M., Laurencin J., Cloetens P., Morel B., Montinaro D., Lefebvre-Joud F. "Impact of Nickel Agglomeration on Solid Oxide Cell Operated in Fuel Cell and Electrolysis Modes." Journal of Power Sources 397 (September 1, 2018): 240-51. https://doi.org/10.1016/j.jpowsour.2018.06.097.

[5] Uhlenbruck S., Moskalewicz T., Jordan N., Penkalla H. -J., Buchkremer H. P. "Element Interdiffusion at Electrolyte-Cathode Interfaces in Ceramic High-Temperature Fuel Cells." Solid State Ionics 180, no. 4 (April 27, 2009): 418-23. https://doi.org/10.1016/j.ssi.2009.01.014.

[6] Yokokawa H., Tu H., Iwanschitz B, and Mai A. "Fundamental Mechanisms Limiting Solid Oxide Fuel Cell Durability." Journal of Power Sources, Selected papers from the International Workshop on Degradation Issues in Fuel Cells, 182, no. 2 (August 1, 2008) 400-412. https://doi.org/10.1016/j.jpowsour.2008.02.016.

[7] Aziz A., Junaida A., Baharuddin N. A., Somalu M. R., and Muchtar A. "Review of Composite Cathodes for Intermediate-Temperature Solid Oxide Fuel Cell Applications." Ceramics International 46, no. 15 (October 15, 2020): 23314-25. https://doi.org/10.1016/j.ceramint.2020.06.176.

[8] Jiang S. P. "Development of Lanthanum Strontium Cobalt Ferrite Perovskite Electrodes of Solid Oxide Fuel Cells - A Review." International Journal of Hydrogen Energy 44, no. 14 (March 15, 2019): 7448-93. https://doi.org/10.1016/j.ijhydene.2019.01.212.

[9] Xia, C., and M. Liu. "Novel Cathodes for Low-Temperature Solid Oxide Fuel Cells." Advanced Materials 14, no. 7 (2002): 521-23. https://doi.org/10.1002/1521-4095(20020404)14:7<521::AID-ADMA521>3.0.CO;2-C

[10] Sun C., Hui R., Roller J. "Cathode Materials for Solid Oxide Fuel Cells: A Review." Journal of Solid State Electrochemistry 14, no. 7 (July 1, 2010): 1125-44. https://doi.org/10.1007/s10008-009-0932-0.

[11] Tietz, F., Haanappel V. A. C., Mai A., Mertens J., Stöver D. "Performance of LSCF Cathodes in Cell Tests." Journal of Power Sources, Selected papers from the 2nd 
France-Deutschland Fuel Cell Conference, 156, no. 1 (May 19, 2006): 20-22. https://doi.org/10.1016/j.jpowsour.2005.08.015.

[12] Frey C. E., Fang Q., Sebold D., Blum L., Menzler N. H. "A Detailed Post Mortem Analysis of Solid Oxide Electrolyzer Cells after Long-Term Stack Operation." Journal of The Electrochemical Society 165, no. 5 (April 6, 2018): F357. https://doi.org/10.1149/2.0961805jes.

[13] Laurencin J., Hubert M., Ferreira Sanchez D., Pylypko S., Morales M., Morata A., Morel B., Montinaro D., Lefebvre-Joud F., Siebert E. "Degradation Mechanism of $\mathrm{La}_{0.6} \mathrm{Sr}_{0.4} \mathrm{Co}_{0.2} \mathrm{Fe}_{0.8} \mathrm{O}_{3-\delta} / \mathrm{Gd}_{0.1} \mathrm{Ce}_{0.9} \mathrm{O}_{2-\delta}$ Composite Electrode Operated under Solid Oxide Electrolysis and Fuel Cell Conditions." Electrochimica Acta 241 (July 1, 2017): 459-76. https://doi.org/10.1016/j.electacta.2017.05.011.

[14] Kim D., Park J. W., Yun B.-H., Park J. H., Lee K. T. "Correlation of Time-Dependent Oxygen Surface Exchange Kinetics with Surface Chemistry of $\mathrm{La}_{0.6} \mathrm{Sr}_{0.4} \mathrm{Co}_{0.2} \mathrm{Fe}_{0.8} \mathrm{O}_{3-\delta}$ Catalysts." ACS Applied Materials \& Interfaces 11, no. 35 (September 4, 2019): 3178692. https://doi.org/10.1021/acsami.9b06569.

[15] Wang H. and Barnett S. A. "Degradation Mechanisms of Porous $\mathrm{La}_{0.6} \mathrm{Sr}_{0.4} \mathrm{Co}_{0.2} \mathrm{Fe}_{0.8} \mathrm{O}_{3-\delta}$ Solid Oxide Fuel Cell Cathodes." Journal of The Electrochemical Society 165, no. 7 (May 22, 2018): F564. https://doi.org/10.1149/2.1211807jes.

[16] Pan Z., Liu Q., Zhang L., Zhang X., Chan S. H. "Effect of Sr Surface Segregation of $\mathrm{La}_{0.6} \mathrm{Sr}_{0.4} \mathrm{Co}_{0.2} \mathrm{Fe}_{0.8} \mathrm{O}_{3-\delta}$ Electrode on Its Electrochemical Performance in SOC." Journal of The Electrochemical Society 162, no. 12 (September 1, 2015): F1316. https://doi.org/10.1149/2.0371512jes.

[17] Adler, S. B., Lane J. A., and Steele B. C. H. "Electrode Kinetics of Porous Mixed- Conducting Oxygen Electrodes." Journal of The Electrochemical Society 143, no. 11 (November 1, 1996): 3554. https://doi.org/10.1149/1.1837252.

[18] Prestat M., Koenig J.-F., Gauckler L. J. "Oxygen Reduction at Thin Dense $\mathrm{La}_{0.52} \mathrm{Sr}_{0.48} \mathrm{Co}_{0.18} \mathrm{Fe}_{0.82} \mathrm{O}_{3-\delta}$ Electrodes: Part I: Reaction Model and Faradaic Impedance." Journal of Electroceramics 18, no. 1-2 (April 19, 2007): 87-101. https://doi.org/10.1007/s10832-007-9012-y.

[19] Baumann F. S., Fleig J., Cristiani G., Stuhlhofer B., Habermeier H.-U., Maier J. "Quantitative Comparison of Mixed Conducting SOFC Cathode Materials by Means of Thin Film Model Electrodes." Journal of The Electrochemical Society 154, no. 9 (July 17, 2007): B931. https://doi.org/10.1149/1.2752974.

[20] Grunbaum N., Dessemond L., Fouletier J., Prado F., Mogni L., Caneiro A. "Rate Limiting Steps of the Porous $\mathrm{La}_{0.78} \mathrm{Sr}_{0.2} \mathrm{Co}_{0.2} \mathrm{Fe}_{0.8} \mathrm{O}_{3-\delta}$ Electrode Material." Solid State $\begin{array}{llllll}\text { Ionics } & 180, \quad \text { no. } & 28 & \text { (November } 14,2009): & 12\end{array}$ https://doi.org/10.1016/j.ssi.2009.09.005.

[21] Laurencin J., Hubert M., Couturier K., Le Bihan T., Cloetens P., Lefebvre-Joud F., Siebert E. "Reactive Mechanisms of LSCF Single-Phase and LSCF-CGO Composite Electrodes Operated in Anodic and Cathodic Polarisations." Electrochimica Acta 174 (August 20, 2015): 1299-1316. https://doi.org/10.1016/j.electacta.2015.06.080.

[22] Monaco F., Tezyk V., Siebert E., Pylypko S., Morel B., Vulliet J., Le Bihan T., Lefebvre-Joud F., Laurencin J. "Experimental Validation of a $\mathrm{La}_{0.6} \mathrm{Sr}_{0.4} \mathrm{Co}_{0.2} \mathrm{Fe}_{0.8} \mathrm{O}_{3-\delta}$ Electrode Model Operated in Electrolysis Mode: Understanding the Reaction Pathway under Anodic Polarization." Solid State Ionics 319 (June 1, 2018): 234-46.

[23] Effori, E., Moussaoui H., Monaco F., Sharma R. K., Debayle J., Gavet Y., Delette G. and Laurencin L. "Reaction Mechanism and Impact of Microstructure on Performances for the LSCF-CGOComposite Electrode in Solid Oxide Cells." Fuel Cells 19, no. 4 (2019): 429-44. https://doi.org/10.1002/fuce.201800185.

[24] Effori, E., Laurencin J., Da Rosa Silva E., Hubert M., David T., Petitjean M., Geneste G., 
Dessemond L., and Siebert E. "An Elementary Kinetic Model for the LSCF and LSCFCGO Electrodes of Solid Oxide Cells: Impact of Operating Conditions and Degradation on the Electrode Response." Journal of The Electrochemical Society 168, no. 4 (April 2021): 044520. https://doi.org/10.1149/1945-7111/abf40a.

[25] Bebelis, S., Kotsionopoulos N., Mai A., Tietz F. "Electrochemical Characterization of Perovskite-Based SOFC Cathodes." Journal of Applied Electrochemistry 37, no. 1 (December 14, 2006): 15-20. https://doi.org/10.1007/s10800-006-9215-y.

[26] Leone P., Santarelli M., Asinari P., Calì M., and Borchiellini R.. "Experimental Investigations of the Microscopic Features and Polarization Limiting Factors of Planar SOFCs with LSM and LSCF Cathodes." Journal of Power Sources 177, no. 1 (February 15, 2008): 111-22. https://doi.org/10.1016/j.jpowsour.2007.11.021.

[27] Chen J., Wan D., Sun X., Li B., Lu M. "Electrochemical Impedance Spectroscopic Characterization of Impregnated $\mathrm{La}_{0.78} \mathrm{Sr}_{0.2} \mathrm{Co}_{0.2} \mathrm{Fe}_{0.8} \mathrm{O}_{3-\delta}$ Cathode for IntermediateTemperature SOFCs.” International Journal of Hydrogen Energy 43, no. 20 (May 17, 2018): 9770-76. https://doi.org/10.1016/j.ijhydene.2018.03.223.

[28] Chen X. J., Chan S. H., Khor K. A. "Cyclic Voltammetry of (La,Sr)MnO 3 Electrode on YSZ Substrate." Solid State Ionics 164, no. 1 (October 1, 2003): 17-25. https://doi.org/10.1016/j.ssi.2003.08.006.

[29] Ding X., Kong X., Jiang J., Cui C. "Evaluation of Sr Substituted $\mathrm{Nd}_{2} \mathrm{CuO}_{4}$ as a Potential Cathode Material for Intermediate-Temperature Solid Oxide Fuel Cells." International Journal of Hydrogen Energy, $4^{\text {th }}$ Dubrovnik Conference, 34, no. 16 (August 1, 2009): 6869-75. https://doi.org/10.1016/j.ijhydene.2009.06.041.

[30] Sapountzi F. M., Brosda S., Papazisi K. M., Balomenou S. P., Tsiplakides D. "Electrochemical Performance of $\mathrm{La}_{0.75} \mathrm{Sr}_{0.25} \mathrm{Cr}_{0.9} \mathrm{Mn}_{0.1} \mathrm{O}_{3}$ Perovskites as SOFC Anodes in $\mathrm{CO} / \mathrm{CO}_{2}$ Mixtures." Journal of Applied Electrochemistry 42, no. 9 (September 2012): 727-35. https://doi.org/10.1007/s10800-012-0459-4.

[31] Bebelis, S., Kournoutis V., Mai A., Tietz F. "Cyclic Voltammetry of $\mathrm{La} 0.78 \mathrm{Sr} 0.2 \mathrm{FeO} 3-\delta$ and $\mathrm{La}_{0.78} \mathrm{Sr}_{0.2} \mathrm{Co}_{0.2} \mathrm{Fe}_{0.8} \mathrm{O}_{3-\delta}$ Electrodes Interfaced to CGO/YSZ." Solid State Ionics, Solid State Ionics 16: Proceedings of the 16th International Conference on Solid State Ionics (SSI-16), Part I, 179, no. 21 (September 15, 2008): 1080-84. https://doi.org/10.1016/j.ssi.2008.02.028.

[32] Kournoutis V. Ch., Tietz F., Bebelis S. "Cyclic Voltammetry Characterization of a $\mathrm{La}_{0.8} \mathrm{Sr}_{0.2} \mathrm{Co}_{0.2} \mathrm{Fe}_{0.8} \mathrm{O}_{3-\delta}$ Electrode Interfaced to $\mathrm{CGO} / \mathrm{YSZ}$." Solid State Ionics 197, no. 1 (August 25, 2011): 13-17. https://doi.org/10.1016/j.ssi.2011.06.007.

[33] Siebert E., Roux C., Boréave A., Gaillard F., Vernoux P. "Oxido-Reduction Properties of $\mathrm{La}_{0.7} \mathrm{Sr}_{0.3} \mathrm{Co}_{0.8} \mathrm{Fe}_{0.2} \mathrm{O}_{3-\delta}$ Perovskite Oxide Catalyst." Solid State Ionics 183, no. 1 (February 11, 2011): 40-47. https://doi.org/10.1016/j.ssi.2010.11.012.

[34] Tezyk, V., Rossignol C., Sergent N., Djurado E., Laurencin J., Siebert E. "Cyclic Voltammetry and High-Frequency Series Resistance of $\mathrm{La}_{0.6} \mathrm{Sr}_{0.4} \mathrm{Co}_{0.2} \mathrm{Fe}_{0.8} \mathrm{O}_{3-\delta}$ Electrode Deposited on GDC: Effect of the Electrode Microstructure and the Oxygen Partial Pressure." Electrochimica Acta 304 (May 1, 2019): 312-22. https://doi.org/10.1016/j.electacta.2019.02.066.

[35] Hubert M., Laurencin J., Cloetens P., da Silva J. C., Lefebvre-Joud F., Bleuet P., Nakajo A., Siebert E. "Role of Microstructure on Electrode Operating Mechanisms for Mixed Ionic Electronic Conductors: From Synchrotron-Based 3D Reconstruction to Electrochemical Modeling." Solid State Ionics 294 (October 15, 2016): 90-107. https://doi.org/10.1016/j.ssi.2016.07.001.

[36] Flura, A., Nicollet C., Vibhu V., Zeimetz B., Rougier A., Bassat J.-M., and Grenier J.-C. "Application of the Adler-Lane-Steele Model to Porous La2NiO4+ $\delta$ SOFC Cathode: Influence of Interfaces with Gadolinia Doped Ceria." Journal of The Electrochemical 
Society 163, no. 6 (March 19, 2016): F523. https://doi.org/10.1149/2.0891606jes.

[37] Endler-Schuck C., Joos J., Niedrig C., Weber A., Ivers-Tiffée E. "The Chemical Oxygen Surface Exchange and Bulk Diffusion Coefficient Determined by Impedance Spectroscopy of Porous $\mathrm{La}_{0.58} \mathrm{Sr}_{0.4} \mathrm{Co}_{0.2} \mathrm{Fe}_{0.8} \mathrm{O}_{3-\delta}$ (LSCF) Cathodes." Solid State Ionics 269 (January 1, 2015): 67-79. https://doi.org/10.1016/j.ssi.2014.11.018.

[38] Nielsen J., and Hjelm J. "Impedance of SOFC Electrodes: A Review and a Comprehensive Case Study on the Impedance of LSM:YSZ Cathodes." Electrochimica Acta $115 \quad$ (January 1, 2014): 31-45. https://doi.org/10.1016/j.electacta.2013.10.053.

[39] Miyoshi K., Miyamae T., Iwai H., Saito M., Kishimoto M., and Yoshida H. "Exchange Current Model for (La0.8Sr0.2)0.95MnO3 (LSM) Porous Cathode for Solid Oxide Fuel Cells.” Journal of Power Sources 315 (May 31, 2016): 63-69. https://doi.org/10.1016/j.jpowsour.2016.02.076.

[40] Donazzi A., Cordaro G., Baricci A., Ding Z.-B., Maestri M. "A Detailed Kinetic Model for the Reduction of Oxygen on LSCF-GDC Composite Cathodes." Electrochimica Acta 335 (March 1, 2020): 135620. https://doi.org/10.1016/j.electacta.2020.135620.

[41] Ma L., Priya P., Aluru N. R.. "A Multiscale Model for Electrochemical Reactions in LSCF Based Solid Oxide Cells." Journal of The Electrochemical Society 165, no. 14 (November 6, 2018): F1232. https://doi.org/10.1149/2.0921814jes.

[42] Fleig, J., Merkle R., Maier J. "The p(O2) Dependence of Oxygen Surface Coverage and Exchange Current Density of Mixed Conducting Oxide Electrodes: Model Considerations." Physical Chemistry Chemical Physics 9, no. 21 (2007): 2713-23. https://doi.org/10.1039/B618765J.

[43] Fleig J. "On the Current-Voltage Characteristics of Charge Transfer Reactions at Mixed Conducting Electrodes on Solid Electrolytes." Phys. Chem. Chem. Phys. 7, no. 9 (2005): 2027-37. https://doi.org/10.1039/B501086A.

[44] Gong M., Gemmen R. S., Mebane D. S., Gerdes K., and Liu X. "Simulation of SurfacePotential Driven ORR Kinetics on SOFC Cathode with Parallel Reaction Pathways." Journal of The Electrochemical Society 161, no. 3 (January 17, 2014): F344. https://doi.org/10.1149/2.104403jes.

[45] Montella C., Tezyk V., Effori E., Laurencin J., Siebert E. "Linear Sweep and Cyclic Voltammetry of Porous Mixed Conducting Oxygen Electrode: Formal Study of Insertion, Diffusion and Chemical Reaction Model." Solid State Ionics 359 (January 1, 2021): 115485. https://doi.org/10.1016/j.ssi.2020.115485.

[46] Rutman J. and Riess I. "Placement of Reference Electrode in Solid State Electrolyte Cells." Solid State Ionics, Solid State Ionics 16: Proceedings of the $16^{\text {th }}$ International Conference on Solid State Ionics (SSI-16), Part I, 179, no. 21 (September 15, 2008): 913-18. https://doi.org/10.1016/j.ssi.2008.01.071.

[47] Hashimoto S., Fukuda Y., Kuhn M., Sato K., Yashiro K., Mizusaki J. "Thermal and Chemical Lattice Expansibility of $\mathrm{La}_{0.6} \mathrm{Sr}_{0.4} \mathrm{Co}_{1-\mathrm{y}} \mathrm{Fe}_{\mathrm{y}} \mathrm{O}_{3-\delta}(\mathrm{y}=0.2,0.4,0.6$ and 0.8)." Solid State Ionics 186, no. 1 (March 25, 2011): 37-43. https://doi.org/10.1016/j.ssi.2011.01.014.

[48] Rutman J., and Riess I. "Placement of Reference Electrode in Solid Electrolyte Cells." Electrochimica Acta 52, no. 20 (June 10, 2007): 6073-83.

https://doi.org/10.1016/j.electacta.2007.03.033.

[49] Wang G., Wu W., Guan W., Jin L., and Wang W. G. "Effect of Conductivity and Adhesive Properties of Cathode Current-Collecting Layer on Cell Performance inside Stack for Planar Solid Oxide Fuel Cells." Ceramics International 40, no. 7, Part (August 1, 2014): 11023-30. https://doi.org/10.1016/j.ceramint.2014.03.117. 
[50] Liu J., Co A. C., Paulson S., Birss V. I. "Oxygen Reduction at Sol-Gel Derived $\mathrm{La}_{0.8} \mathrm{Sr}_{0.2} \mathrm{Co}_{0.8} \mathrm{Fe}_{0.2} \mathrm{O}_{3}$ Cathodes." Solid State Ionics 177, no. 3 (January 31, 2006): 37787. https://doi.org/10.1016/j.ssi.2005.11.005.

[51] Lust E., Küngas R., Kivi I., Kurig H., Möller P., Anderson E., Lust K., Tamm K., Samussenko A., Nurk G. "Electrochemical and Gas Phase Parameters of Cathodes for Intermediate Temperature Solid Oxide Fuel Cells." Electrochimica Acta, Selection of papers from the $7^{\text {th }}$ ISE Spring Meeting22-25 March 2009, Szczyrk, Poland, 55, no. 26 (November 1, 2010): 7669-78. https://doi.org/10.1016/j.electacta.2009.11.007.

[52] Bard A. and Faulkner L. Wiley.com. "Electrochemical Methods: Fundamentals and Applications, 2nd Edition | Wiley.” Accessed May 21, 2021.

[53] Guo S., Puleo F., Wang L., Wu H., and Liotta L. F. "La0.6Sr0.4Co0.2Fe0.79M0.01O3- $\delta$ $(\mathrm{M}=\mathrm{Ni}, \mathrm{Pd})$ Perovskites Synthesized by Citrate-EDTA Method: Oxygen Vacancies Effect on Electrochemical Properties." Advanced Powder Technology 29, no. 11 (November 1, 2018): 2804-12. https://doi.org/10.1016/j.apt.2018.07.029. 
Tab. I Reaction equations of the elementary model. The corresponding notation is illustrated in the List of Symbols.

\begin{tabular}{|c|c|}
\hline $\mathbf{N}^{\circ}$ & Reaction mechanism \\
\hline R1 & $O_{o}^{x}(C G O)+V_{o}^{\cdot \bullet}(L S C F) \stackrel{k_{+}}{\leftrightarrow} O_{o}^{x}(L S C F)+V_{o}^{\cdot \bullet}(C G O)$ \\
\hline R2 & $O_{o}^{x}(L S C F)+1 h^{\bullet}+1 s_{L S C F} k_{o x}^{L S C F / g a s} \underset{k_{r e d}^{L S C F / g a s}}{\leftrightarrow} V_{o}^{\bullet \cdot(L S C F)+O^{-}-S_{L S C F}}$ \\
\hline R3 & $O_{o}^{x}(C G O)+1 h^{\bullet}+1 s_{L S C F} \underset{k_{\text {red }}^{T P B l s}}{k_{o x}^{T P B l s}} O^{-}-s_{L S C F}+V_{o}^{*}(C G O)$ \\
\hline R4 & $O^{-}-s_{L S C F}+1 h^{\cdot} k_{k_{\text {den }}}^{\leftrightarrow} O-s_{L S C F}$ \\
\hline R5 & $20-s_{L S C F} \stackrel{k_{a s s}}{\leftrightarrow} O_{2}-s_{L S C F}+1 s_{L S C F}$ \\
\hline R6 & $O_{2}-s_{L S C F} \stackrel{k_{d e s}}{\leftrightarrow} O_{2}($ gas $)+1 s_{L S C F}$ \\
\hline
\end{tabular}


Tab. II Model input parameters, at $700{ }^{\circ} \mathrm{C}$ and $P_{O_{2}}=0.1 \mathrm{~atm}$, for the numerical version of the semi-analytical model (model-I).

\begin{tabular}{|c|c|c|}
\hline $\begin{array}{c}\text { Analytical model: parameter at } 700^{\circ} \mathrm{C} \text {, } \\
\qquad P_{O_{2}}=0.1 \mathrm{~atm}\end{array}$ & Value & Unit \\
\hline $\begin{array}{c}\text { Maximum oxygen concentration in the } \\
\operatorname{LSCF}\left(C_{O_{O}^{x}}^{\max }\right)\end{array}$ & 83108 & $\left(\mathrm{~mol} \cdot \mathrm{m}^{-3}\right)$ \\
\hline $\begin{array}{l}\text { Equilibrium oxygen concentration in the } \\
\qquad \operatorname{LSCF}\left(C_{O_{O}^{x}}^{e q}\right)\end{array}$ & 82491 & $\left(\mathrm{~mol} \cdot \mathrm{m}^{-3}\right)$ \\
\hline LSCF chemical diffusivity $\left(D_{\text {chem }}\right)$ & $3.7 \times 10^{-10}$ & $\left(\mathrm{~m}^{2} \cdot \mathrm{s}^{-1}\right)$ \\
\hline Ionic transfer kinetic constant $\left(k_{+}\right)$ & NOT LIMITING & $\left(\mathrm{mol} \cdot \mathrm{m}^{-1} \cdot \mathrm{s}^{-1}\right)$ \\
\hline LSCF chemical constant $\left(k_{\text {chem }}\right)$ & $1.23 \times 10^{-7}$ & $\mathrm{~m} \cdot \mathrm{s}^{-1}$ \\
\hline Charge transfer coefficient $(\alpha)$ & 0.5 & $(-)$ \\
\hline Electrolyte thickness $\left(\ell_{Y S Z}\right)$ & $1.25 \times 10^{-4}$ & $(\mathrm{~m})$ \\
\hline Contact resistance $\left(R_{C}\right)$ & 0.96 & $\left(\Omega \cdot \mathrm{cm}^{2}\right)$ \\
\hline Ionic conductivity of YSZ $\left(\sigma_{Y S Z}\right)$ & 2.3 & $\left(\mathrm{~S} \cdot \mathrm{m}^{-1}\right)$ \\
\hline Electrode thickness $\left(\ell_{\text {electrolyte }}\right)$ & $3.5 \times 10^{-5}$ & $(\mathrm{~m})$ \\
\hline Volume fraction $\left(\varepsilon_{L S C F}\right)$ & 48.7 & $(\%)$ \\
\hline Tortuosity factor $\left(\tau_{L S C F}\right)$ & 2.84 & $(-)$ \\
\hline LSCF specific surface area $\left(S_{p}^{L S C F}\right)$ & $3.59 \times 10^{6}$ & $\mathrm{~m}^{-1}$ \\
\hline
\end{tabular}




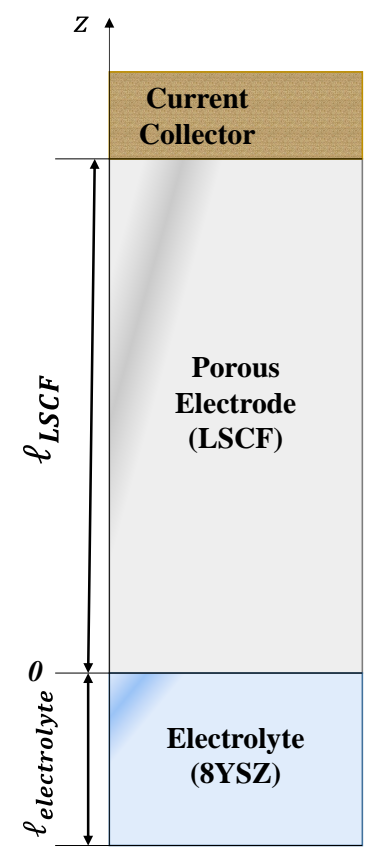

(a)

$$
\left(P_{O_{2}}=c t e\right)
$$

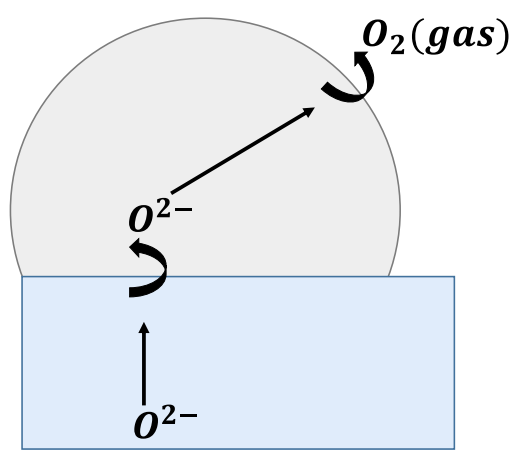

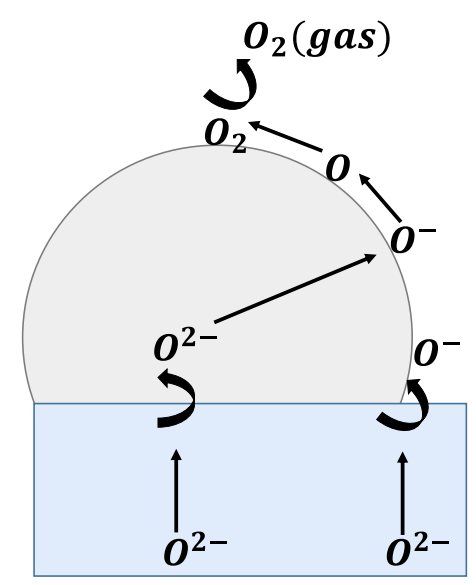

Fig. 1 Schematic representation of the simulated domain (a) with a focus on the reaction mechanism for model-I (b) and model-II (c). For the sake of clarity, the electrons have been omitted. 

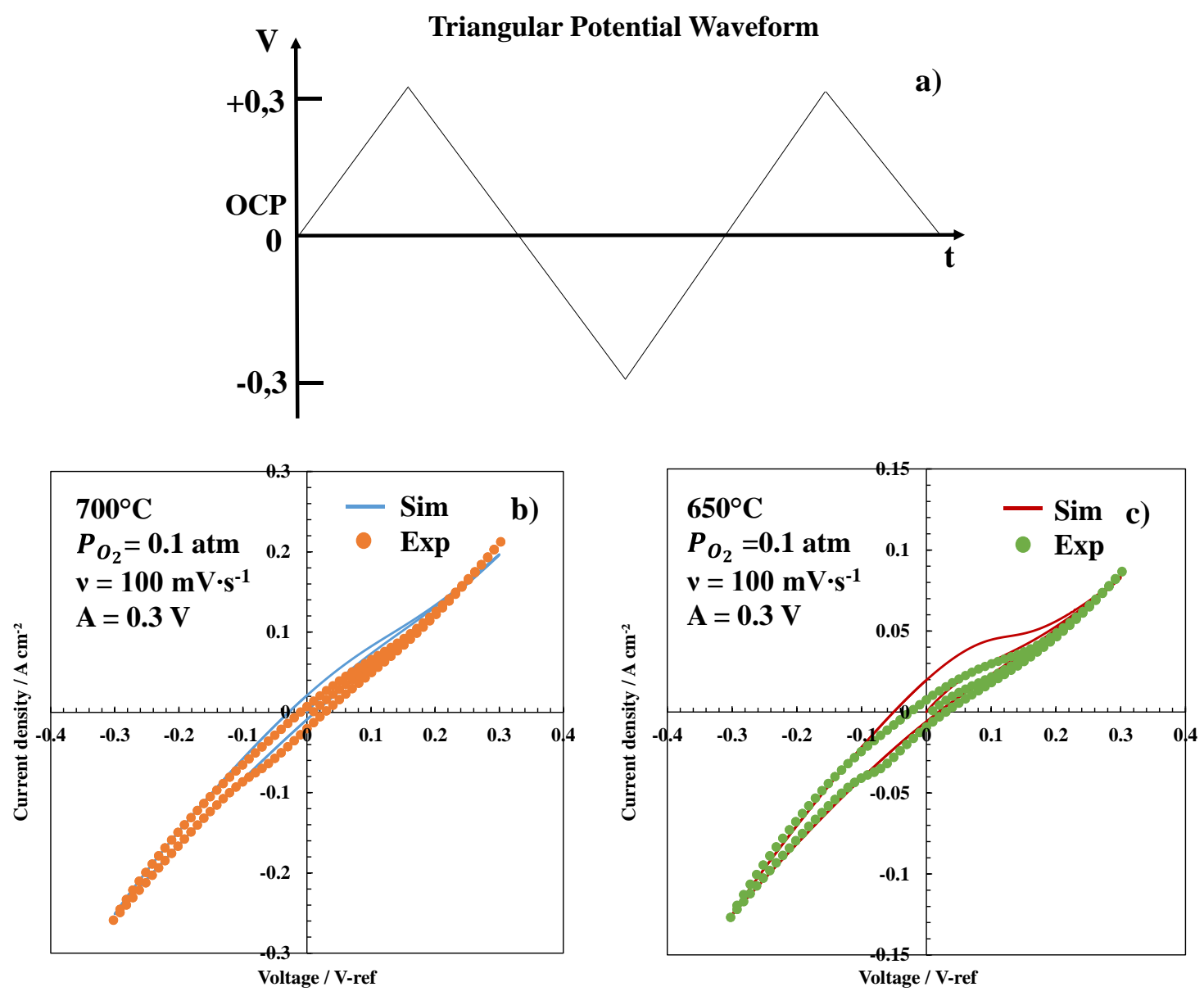

Fig. 2 Experimental and simulated cyclic voltammetry curves, under $P_{O_{2}}=0.1 \mathrm{~atm}$, at 700 ${ }^{\circ} \mathrm{C}$ (b) and $650{ }^{\circ} \mathrm{C}$ (c) for the potential waveform with $v=100 \mathrm{mV} \cdot \mathrm{s}^{-1}$ and $\mathrm{A}=0.3 \mathrm{~V}$ (a). 

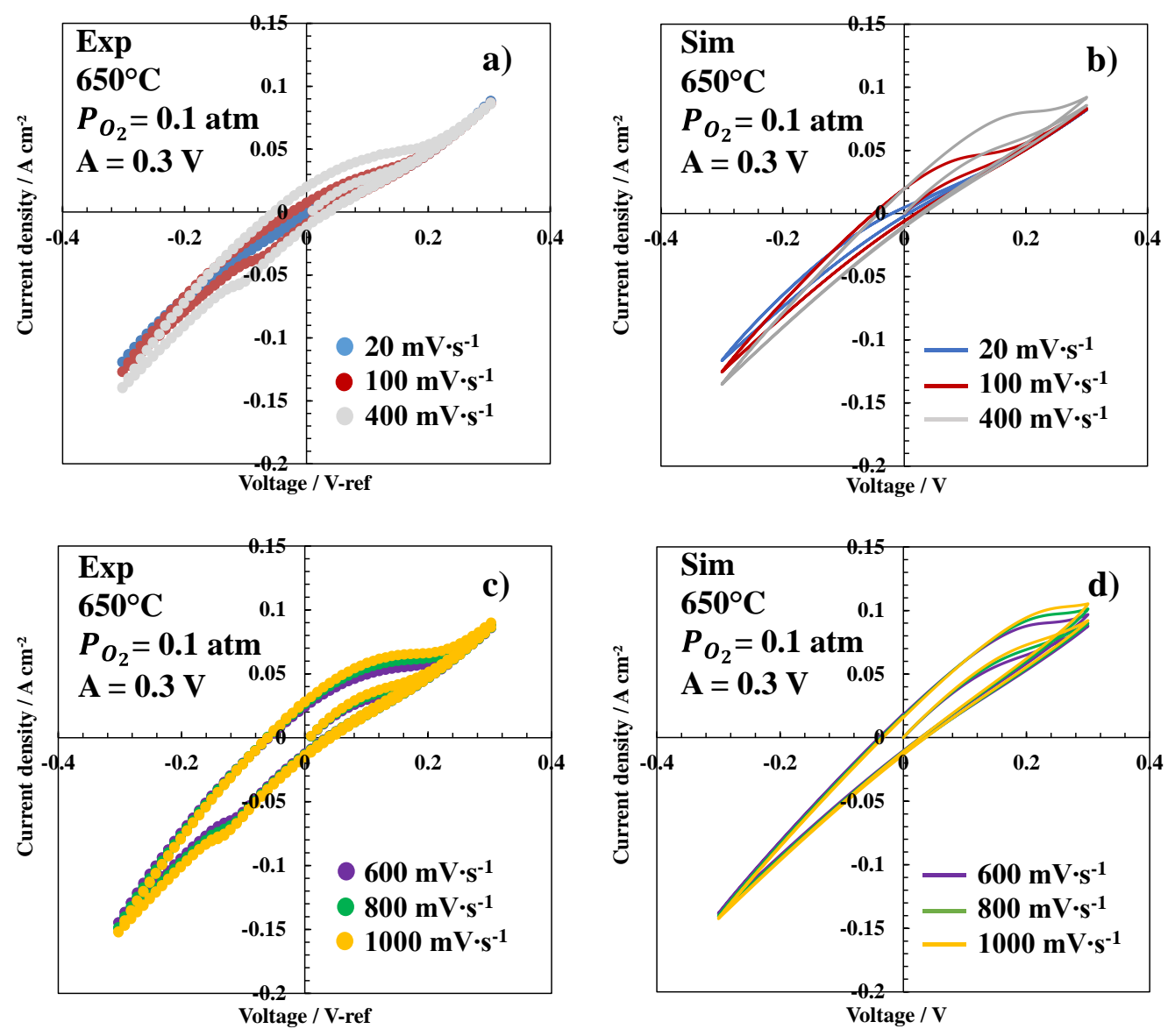

Fig. 3 Experimental (a) and (c) and simulated (b) and (d) cyclic voltammetry curves as a function of the scan rate at $650{ }^{\circ} \mathrm{C}$ and $P_{O_{2}}=0.1 \mathrm{~atm}$. The potential waveform is the same as in Fig. 2a. 

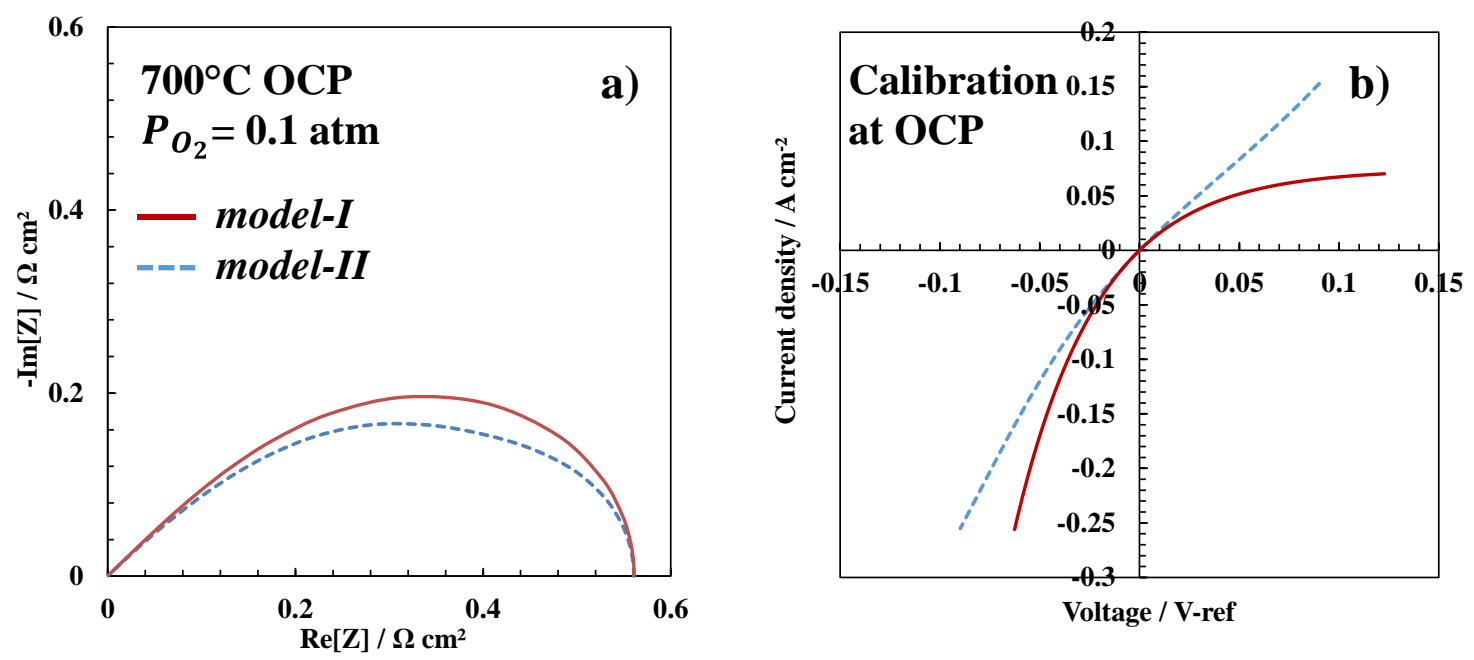

Fig. 4 Impedance diagrams at OCP plotted at $700{ }^{\circ} \mathrm{C}$ and $P_{O_{2}}=0.1 \mathrm{~atm}$ (a). The blue dashed line represents the simulation with model-II, used to predict the LSCF electrode behavior while the red solid line represents the fitting result by model-I. Corresponding polarization curves simulated with model-II (blue dashed line) and model-I (red solid line) (b). 


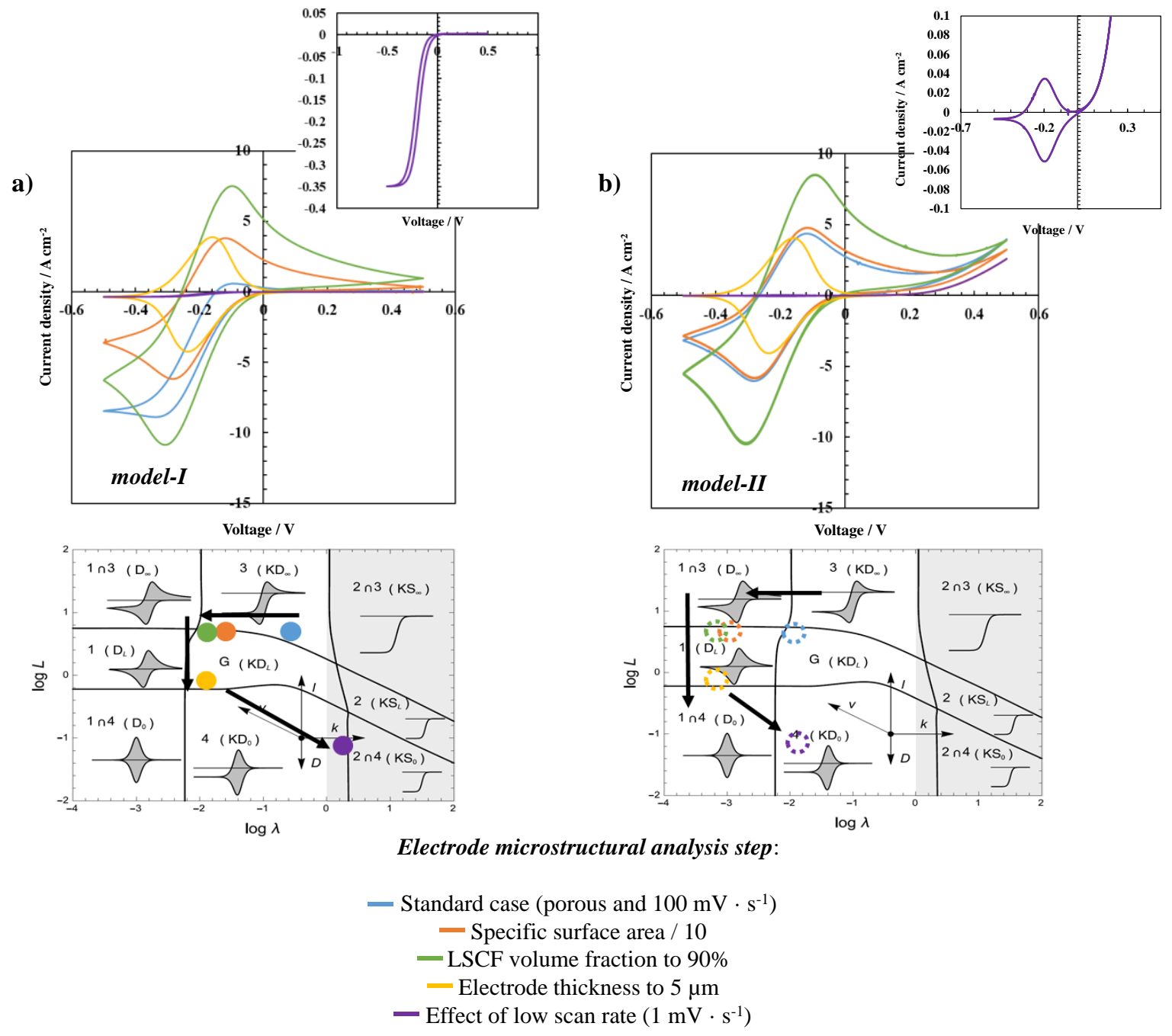

Fig. 5 Evolution of the cyclic voltammetry curves, at $700{ }^{\circ} \mathrm{C}$ and $P_{O_{2}}=0.1$ atm from the case of a porous electrode to the case of a quasi-dense electrode for model-I (a) and model-II (b) without Ohmic losses. The last curve at low scan rate has been magnified and reported in second quarter of both figures. The full circles represent the calculated values of $\lambda$ and $L$ for the analytical model, while the empty circles represent the zone in which the CV curves of the full elementary model can be located. The triangular potential waveform starts in the cathodic direction with $\mathrm{A}=0.5 \mathrm{~V}$. 

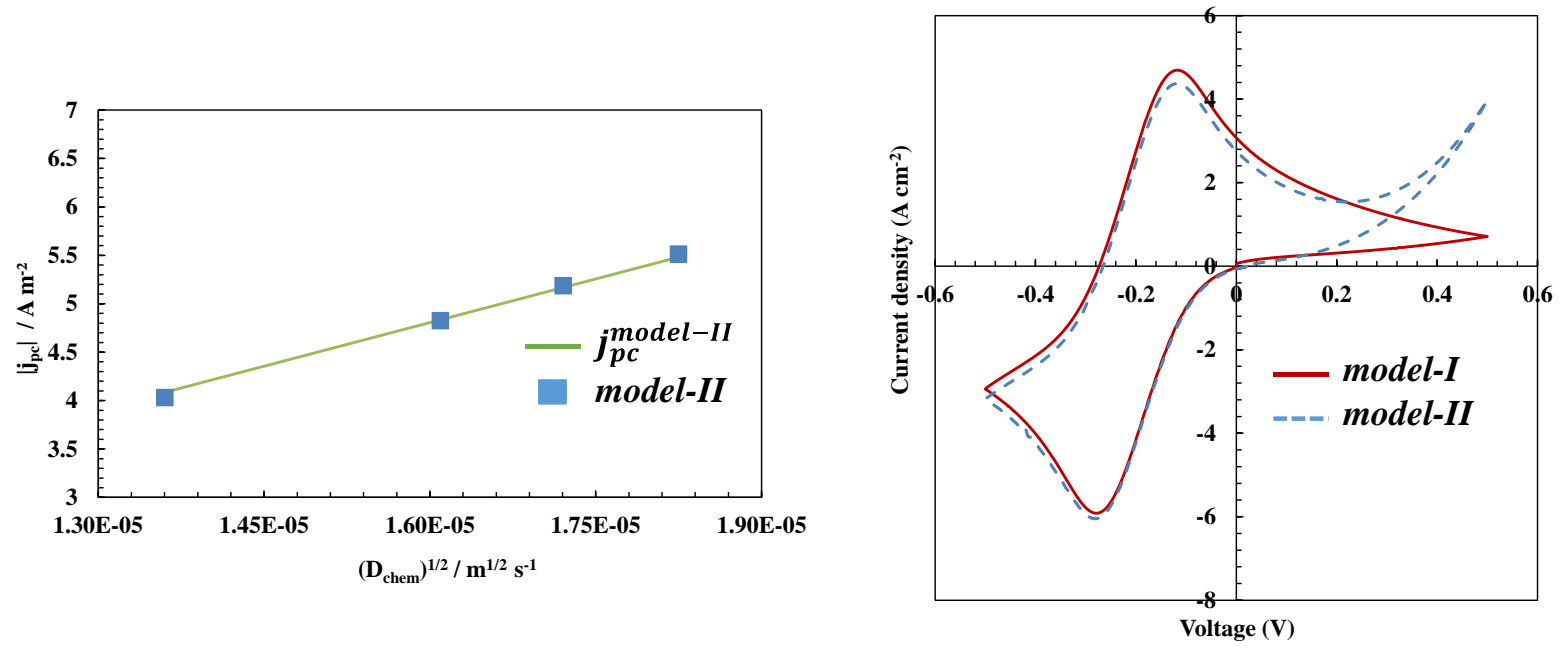

Fig. 6 Current density of the cathodic peak, at $700{ }^{\circ} \mathrm{C}, P_{O_{2}}=0.1 \mathrm{~atm}, v=100 \mathrm{mV} \cdot \mathrm{s}^{-1}$ as a function of the square root of the chemical diffusivity simulated with model-II (blue squares) and fitted with Eq. (11) (solid green line) (a). Comparison of the semi-analytical solution (solid red curve) and full elementary model (dotted blue curve) (b), in zone $1 \cap 3$ without Ohmic losses ( $\ell_{\text {electrolyte }} \rightarrow 0$ and $\left.R_{\text {contact }} \rightarrow 0\right)$. The potential waveform is the same as in Fig. 5. 

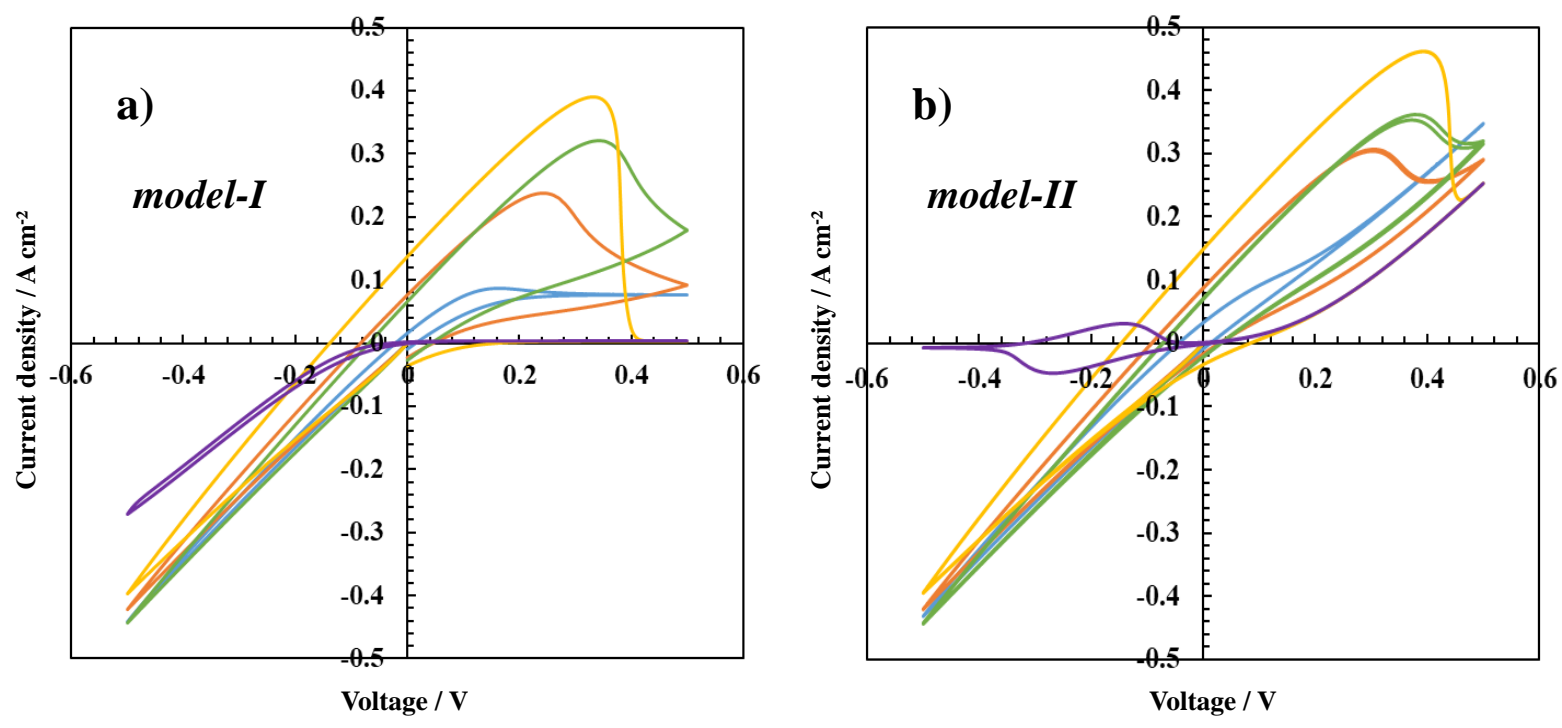

Fig. 7 Evolution of the cyclic voltammetry curves, at $700{ }^{\circ} \mathrm{C}$ and $P_{O_{2}}=0.1 \mathrm{~atm}$, from the case of a porous electrode to the case of a quasi-dense electrode for model-I (a) and model-II (b) by taking into account the Ohmic losses (electrolyte thickness and contact resistance). The same color code than in Fig. 5 has been used for each step of the analysis. The potential waveform is the same as in Fig. 5. 

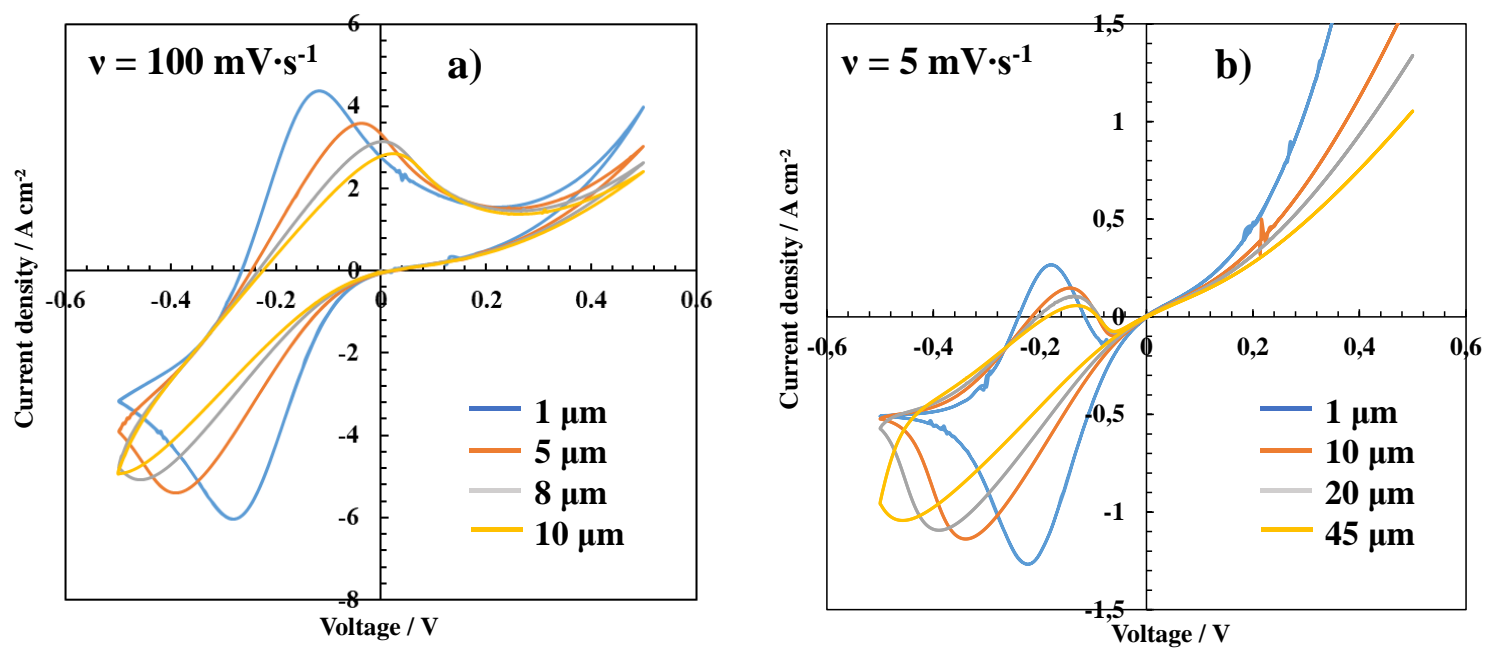

Fig. 8 Effect of the electrolyte thickness on the cyclic voltammetry curves for the standard porous electrode, at $700{ }^{\circ} \mathrm{C}$ and $P_{O_{2}}=0.1 \mathrm{~atm}$, simulated with model-II with a scan rate of 100 $\mathrm{mV} \cdot \mathrm{s}^{-1}$ (a) and $5 \mathrm{mV} \cdot \mathrm{s}^{-1}(\mathrm{~b})$, without contact resistance $\left(R_{\text {contact }} \rightarrow 0\right)$. The potential waveform is the same as in Fig. 5. 


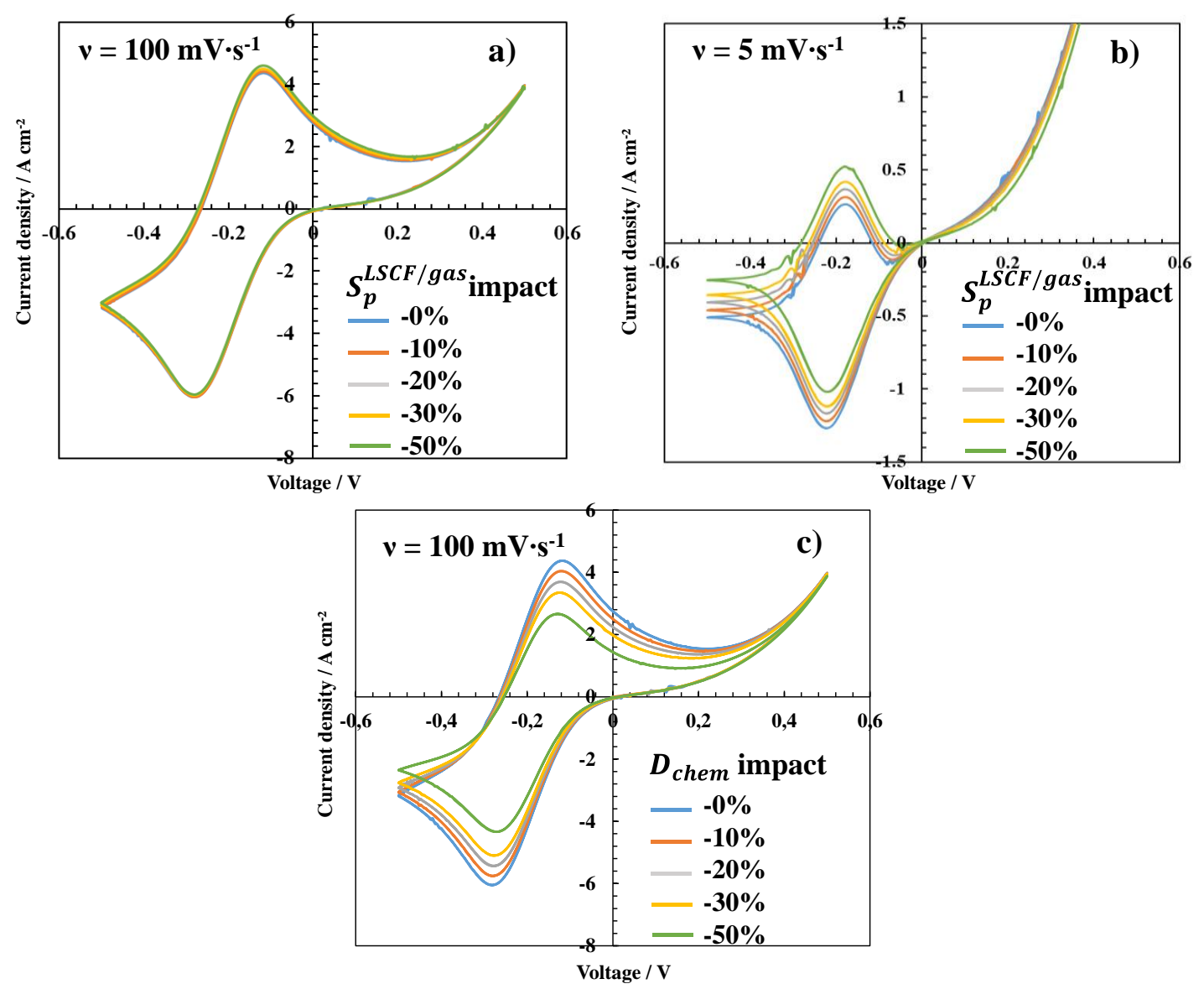

Fig. 9 Study of the impact of the decrease of the specific surface area at $100 \mathrm{mV} \cdot \mathrm{s}^{-1}$ (a) and $5 \mathrm{mV} \cdot \mathrm{s}^{-1}$ (b) and of the loss of ionic conductivity (c). The simulations have been performed with model-II for the porous LSCF electrode at $700{ }^{\circ} \mathrm{C}$ and $P_{O_{2}}=0.1 \mathrm{~atm}$, without Ohmic losses ( $\ell_{\text {electrolyte }} \rightarrow 0$ and $R_{\text {contact }} \rightarrow 0$ ). The potential waveform is the same as in Fig. 5. 


\section{SUPPLEMENTARY}

In Fig. S1, it is shown that the CV curves obtained from the semi-analytical ALS-based model developed in [45] have the same shape as those reported in Fig. 5a. Moreover, the values of the cathodic and anodic peak current density are exactly the same. However, there is a slight mismatch on the values of the peak potential difference, defined by: $\Delta E_{p}=E_{p a}-E_{p c}$, where $E_{p c}$ and $E_{p a}$ are the cathodic and anodic peak potential, respectively. Indeed, it has been found that $\Delta E_{p}$ is always about $50 \mathrm{mV}$ higher with Model-I compared to the semi-analytical ALS-based model. The reason to explain difference is still unclear. It could be due to some numerical uncertainties in the numerical simulations for large perturbations.

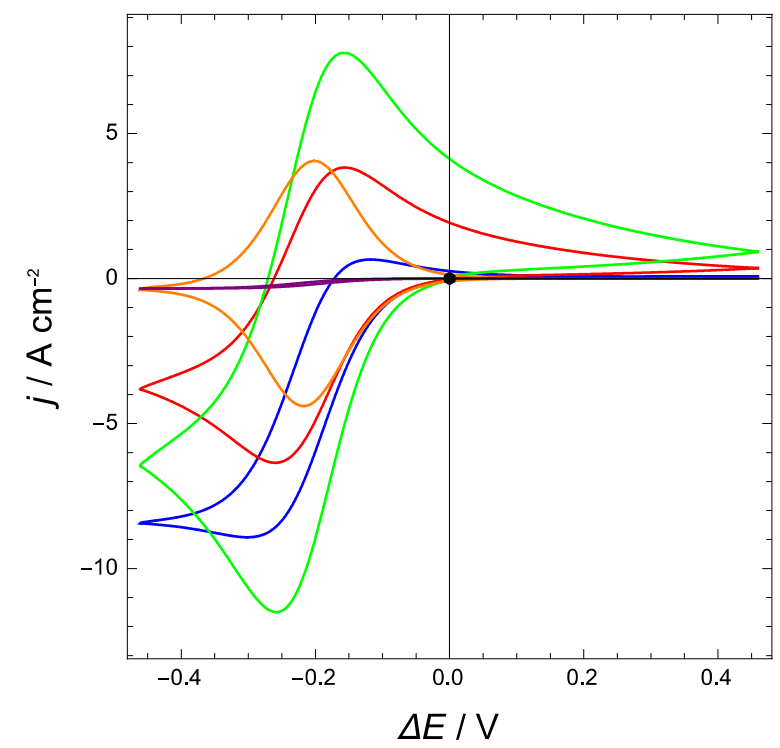

Fig. S1. Cyclic voltammetry curves plotted with the semi-analytical model for the characteristic points of the zone diagram shown in Fig. 5a. The color code is the same as in Fig. 5.

Figure S2 shows the CV curves plotted from the semi-analytical model for the coordinate point in the zone diagram $\log \lambda=-1.29$ and $\log L=-1.17$ (curve on the left). It can be seen that the curve is very similar to that obtained with Model-II (purple curve in Fig. 5b). Moreover, if we increase $\log \lambda$ by 1.6 (curve on the right), we find the curve of Fig. 5a, corresponding to Model-I. One can thus propose that, in the experimental conditions of Fig. 5a, the results from Model-II can be deduced from Model-I by translating from -1.6 on the X-axis in the zone diagram. This result is confirmed in Fig. S3, which shows the CV curves plotted from the semi-analytical model for the characteristics points calculated in Fig. 5a and translated from - 
1.6 on the $\mathrm{x}$-axis. It can be noticed that the voltammograms are very similar to those in Fig. 5b, obtained from Model-II.
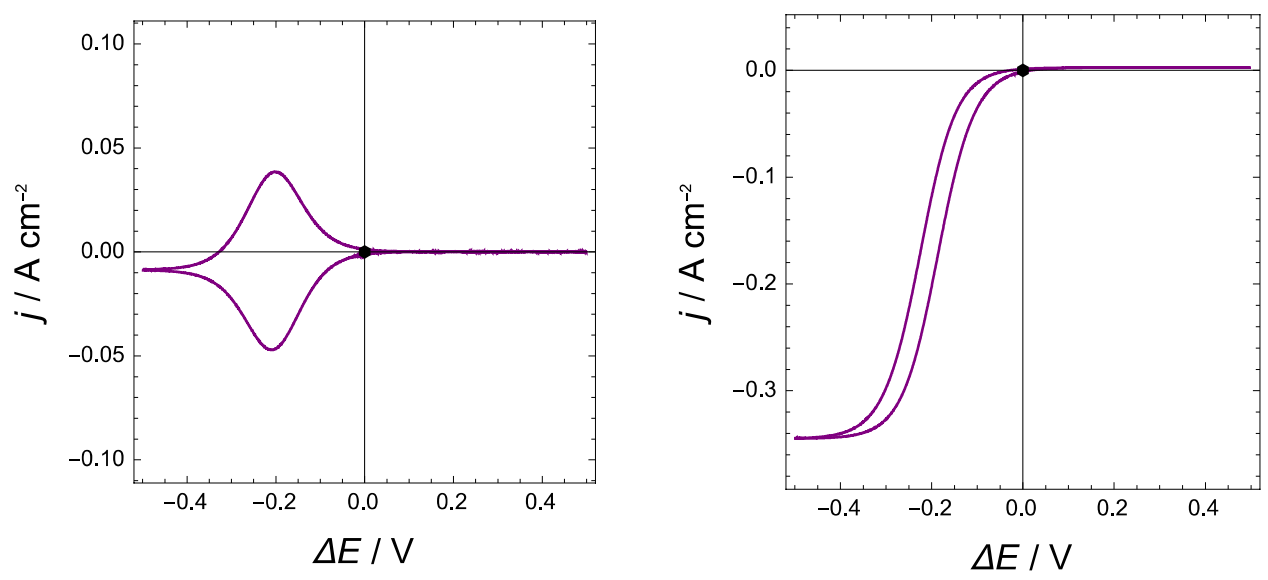

Fig. S2. Cyclic voltammetry curve plotted with the semi-analytical model for the coordinate point $[-1.29 ;-1.17]$ (left) and by translating from 1.6 on the $\mathrm{x}$-axis (right). The color code is the same as in Fig. 5.

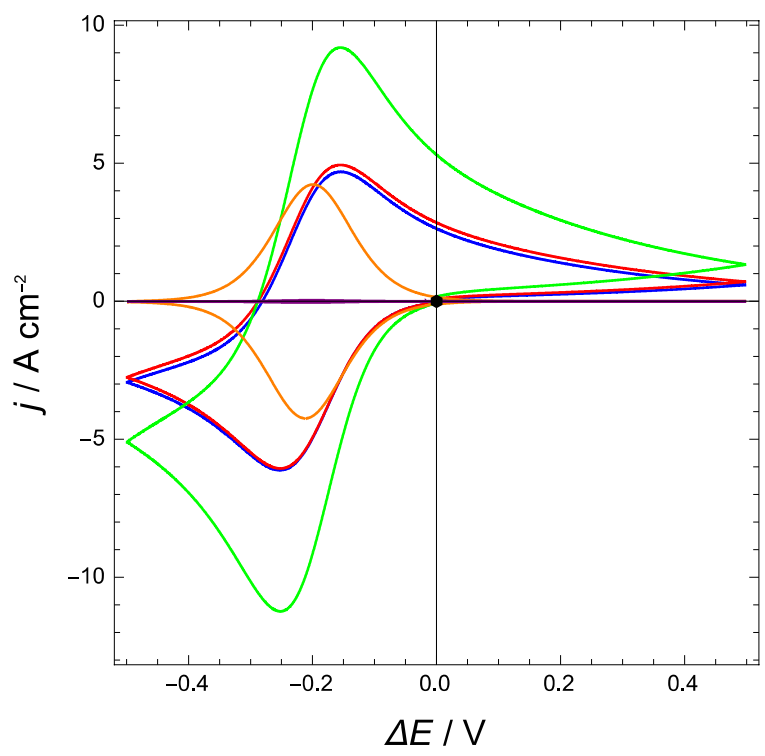

Fig. S3. Cyclic voltammetry curves plotted with the semi-analytical model by translating the point of Fig. 5a from -1.6 on the x-axis. The color code is the same as in Fig. 5.

Fig. S4 shows the determination of $k_{\text {chem }}$ from the fitting with model-I of the cathodic branch of the i-V curve obtained with model-II $\left(k_{\text {chem }}=3.0 \cdot 10^{-8} \mathrm{~m} \cdot \mathrm{s}^{-1}\right)$. The CV response has been calculated using the second calibration for model-I (for $k_{\text {chem }}=3.0 \cdot 10^{-8} \mathrm{~m} \cdot \mathrm{s}^{-1}$ ) without Ohmic losses. The same sensitivity analysis than the one reported in Fig. 5 has been performed to 
mimic the passage from a porous standard electrode to a quasi-dense film (Fig. S5). The study has been repeated taking into account the Ohmic losses in the model (i.e. electrolyte thickness $\ell_{Y S Z}=125 \mu \mathrm{m}$ and contact resistances $R_{c}=0.96 \Omega . \mathrm{cm}^{2}$ ) (Fig. S6).

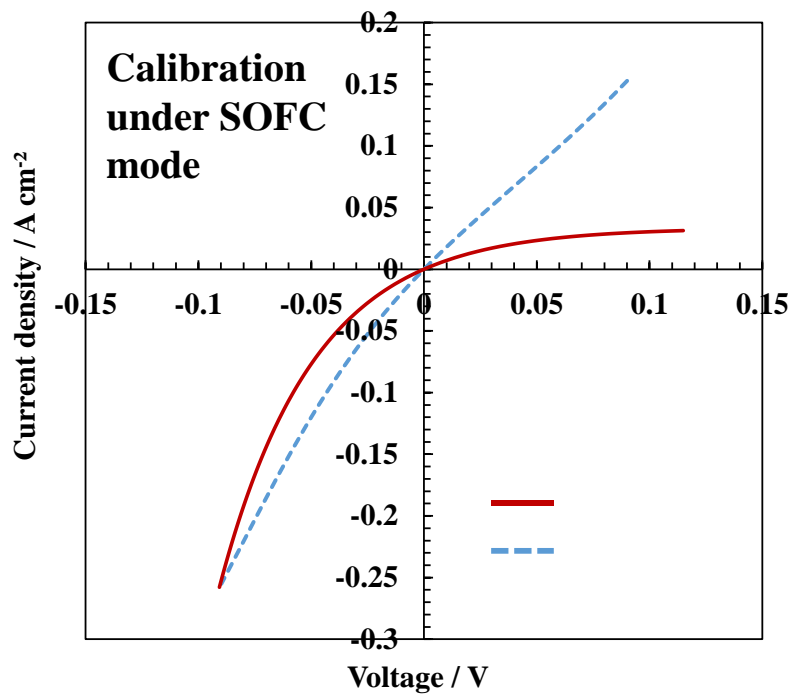

Fig. S4. Calibration of model-I on the cathodic branch of the i-V curve obtained with model-II (at $700^{\circ} \mathrm{C}, P_{O_{2}}=0.1 \mathrm{~atm}$ ) (a). The red solid line represents the simulations with the model-I, while the blue dashed line represents the simulation with model-II. 


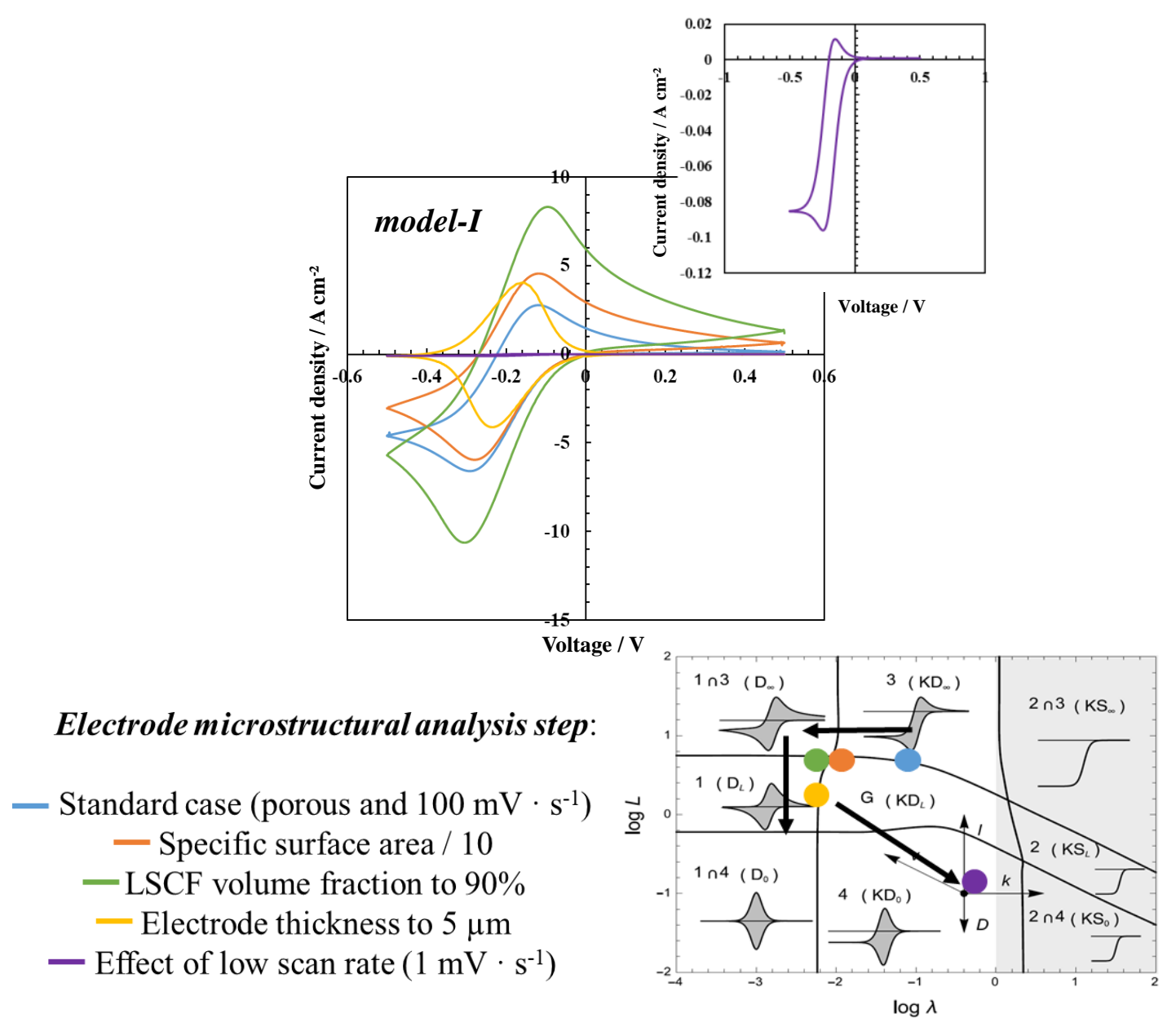

Fig. S5. Cyclic voltammetry curves at $700{ }^{\circ} \mathrm{C}$ and $P_{O_{2}}=0.1 \mathrm{~atm}$ calculated with the second calibration of model- $I$ (for $k_{\text {chem }}=3.0 \cdot 10^{-8} \mathrm{~m} \cdot \mathrm{s}^{-1}$ ) without Ohmic losses $\left(\ell_{Y S Z} \rightarrow 0\right.$ and $R_{C} \rightarrow 0$ ). The passage from a porous electrode to a quasi-dense electrode has been simulated. The last curve at low scan rate has been magnified and reported in the quarter of the figure. The triangular potential waveform starts in the cathodic direction with $\mathrm{A}=0.5 \mathrm{~V}$. 




Fig. S6. Cyclic voltammetry curves at $700^{\circ} \mathrm{C}, P_{O_{2}}=0.1$ atm calculated with the second calibration of model-I (for $k_{\text {chem }}=3.0 \cdot 10^{-8} \mathrm{~m} \cdot \mathrm{s}^{-1}$ ) by taking into account the Ohmic losses (electrolyte thickness and contact resistances). The same color code than in Fig. 5 has been used for each step of the analysis. The potential waveform is the same as in Fig. 5. 